\title{
PEDRO DE NAVARRA: REVISIÓN DE UN HUMANISTA. BIBLIOGRAFÍA REPERTORIADA DE LOS SIGLOS XVI-XVII
}

\author{
Gregorio Cabello Porras \\ Universidad DE Almería
}

\section{Semblanza biográfica}

Como «hombre de ingenio peregrino y raro», nota breve y concisa, pero de gran fecundidad receptiva en los siglos posteriores, lo caracterizaba A. Yepes (1610) en la primera referencia impresa de relieve que tenemos de Pedro de Navarra: ${ }^{1}$ una persona dotada por naturaleza para exprimir la correspondencia que pueda hallarse entre los objetos a los que dedica su labor intelectual para dar «noticia sutil de las cosas altas». Y este despliegue de su ingenio va a abarcar los campos más diversos, todos aquellos cuya suma podrían conferirle la dimensión de la figura del «humanista», en el tránsito desde la época del Emperador al reinado de Felipe II. A. Galland (1618) da cuenta de su especial habilidad para la retórica y la oratoria, y la minuciosa preparación de sus

\footnotetext{
${ }^{1}$ A. de Yepes, Corónica General de la Orden de San Benito, Patriarca de Religiosos. Por el maestro Fray Antonio de Yepes. Tomo III. Centuria III, Irache, Nicolás de Assiayn, 1610, f. 378v.
} 
discursos e intervenciones ante la autoridad pontificia. ${ }^{2}$ A. d'Oihénart (1637) destacaba sus tratados sobre «Filología en lengua española». ${ }^{3}$ Fray Jerónimo de San José, en 1651, anotaba cómo Pedro de Navarra «en ocho diálogos en lengua española discurre con gravedad y erudición sobre los requisitos de la Historia y del historiador». ${ }^{4}$

Nicolás Antonio (1672) hacía hincapié en la enjundia de su doctrina, ${ }^{5}$ que debe entenderse como voluntad de educación y formación moral, ya que los diálogos de los que da cuenta se centran en asuntos tocantes a la validez y utilidad práctica de unas determinadas formulaciones doctrinales: la condición que debe poseer el cronista del príncipe, escindido entre su ética como historiador y su subordinación a los intereses de los mandatarios; las virtudes que esgrime un rústico, en tanto que hombre natural frente a los artificios y la capacidad innata para la doblez del noble, adentrándose en la vertiente del menosprecio del mundo, encarnado en la corte, frente a la alabanza de la órbita del «villano»; o la preparación para la muerte presentada como decálogo de consejos y avisos dirigida a un personaje de una relevancia especial en la corte de Felipe II, el secretario de estado Francisco de Eraso.

\footnotetext{
${ }^{2}$ A. Galland, Mémoires pour l'histoire de la Navarre et de Flandre, contenants le droit du roy au royaume de Navarre..., París, Mathieu Guillemot, 1618, pp. 80-105.

${ }^{3}$ A. d'Oihénart, Notitia utriusque Vasconiae tum Ibericae, tum Aquitanicae, qua praeter situm regionis et alia scitu digna, Navarre Regum, Gasconiae Principum, caeterarumque, iniis, insignium vetustae... (1637). Cito por la reprod. facsímil de la 2. ${ }^{a}$ edición de París, 1656, con estudio preliminar de R. Cierbide, y trad. del texto latino, J. Gorosterratzu, Vitoria-Gasteiz, Eusko Legebiltzarra-Parlamento Vasco, 1992, lib. III, cap. XII, p. 476.

${ }^{4}$ Fray J. de San José, Genio de la historia, Zaragoza, Diego Dormer, 1651, f. 155 v.

${ }^{5}$ Nicolás Antonio, Bibliotheca Hispana Nova sive Hispanorum Scriptorum, II, pp. 220-221. Finalizada en 1672, la primera edición de la Bibliotheca hispana nova tuvo lugar en Roma en 1696. Cito aquí por la edición de Madrid, Joaquín de Ibarra, 1783, en dos tomos. Manejo para ello la reprod. facsimilar de Madrid, Visor Libros, 1996. Contamos ya con la versión traducida, Biblioteca hispana nueva, o de los escritores españoles que brillaron desde el año MD hasta el de MDCLXXXIV, I-II, Madrid, Fundación Universitaria Española, 1999. El bibliófilo español se sitúa en el origen de una de los muchos malentendidos, confusiones, y catalogaciones bibliográficas erróneas que se han transmitido por inercia en torno a la vida y obra de Pedro de Navarra, ya que distingue entre un «PETRUS DE NAVARRA alias LABRIT» y un «PETRUS NAVARRO», como si se trataran de autores distintos. Al primero correspondería la autoría de los Dialogos muy subtiles y notables, Zaragoza, Juan Millán, 1567, que incluirían tres series de diálogos: De qual debe ser el Coronista del Principe, De la diferencia de la vida rustica a la noble y De la preparacion de la muerte. Al segundo, «Petrus Navarro», corresponde la autoría de los Dialogum de Discrimine legendi ac scribendi, Tolosa, Jacobo Colomerio, y los que intitula Dell'Eternita dell'Anima.
} 
I. del Asso $(1794)^{6}$ eleva la condición de su obra al referirse a los «Dialogi Philosophici argumenti, quos Hispano eloquio conscripsit» y destaca uno de los aspectos más significativos para la consideración de su condición de «humanista»: su activa participación en las academias de la época, tanto en España, caso de la academia celebrada en casa de Hernán Cortés, como en Francia, en torno a la figura de su primo, el cardenal Jorge de Armagnac. I. del Asso resalta las materias que en ellas se trataban, todas sobre temas «graves e notables», y se hacía eco de un proceder del que el propio Pedro de Navarra da cuenta en sus escritos: muchos de sus diálogos, unos doscientos que decía haber compuesto, tenían su origen, casi a modo de transcripción, en las conversaciones que en ellas se celebraban. Asimismo, completa el marco de su dimensión como «humanista» atendiendo a la etapa final de la vida del escritor y a las preocupaciones que entonces le embargaban: la filosofía natural y del ser, y la diversidad de religiones que ha traído consigo la difusión de las sectas luteranas y calvinistas, además de su creciente interés, de muy otra índole, sobre el diseño y la arquitectura, incidiendo incluso en aspectos tan concretos y detallistas como la calidad y diversidad de los materiales de construcción, sobre los que mantuvo correspondencia con Felipe II.

Frente a esta visión de Pedro de Navarra, desde el ámbito humanista y literario, frecuentada en la historiografía literaria española, la semblanza que la historiografía francesa da de él guarda rasgos muy diferenciados. En una línea en la que se situarían los acercamientos de A. Galland, O. Raynaldi (1727), ${ }^{7}$ A. de Ruble (1881-1886), ${ }^{8}$ J. Šusta (1904), ${ }^{9}$ J. Lestrade (1913) ${ }^{10}$ y A. Degert (1912 y $1933)^{11}$ se nos muestran los cimientos que posibilitaron la definición de Pedro de

\footnotetext{
${ }^{6}$ I. del Asso y del Río, De libris quibusdam hispaniorum rarioribus disquisitio, Zaragoza, Mariani Miedis, 1794, apdo. LIX «Petrus de Navarra».

${ }^{7}$ O. Raynaldi, Annales ecclesiastici, XXI, 1: Ab anno MDXXXIV, Pauli III usque ad annum MDLXV Maximiliani II, Colonia, Ioannem Wilhelmum Friessem, 1727, n. ${ }^{\circ} 85$.

${ }^{8}$ A. de Ruble, Antoine de Bourbon et Jeanne d'Albret, suite de «Le mariage de Jeanne d'Albret», I-IV, París, Adolphe Labitte, 1881-1886.

${ }^{9}$ J. Šusta, Die Römische Curie und das Concil von Trient unter Pius IV. Actenstücke zur Geschichte des Concils von Trient, I-IV, Viena, Alfred Hölder, k. u. k. Hof-und Universitäts Buchhändler, 1904-1914.

${ }^{10} \mathrm{~J}$. Lestrade, Un curieux groupe d'évêques commingeois. Notices et documents, Saint-Gaudens, Imprimerie et Librairie Abadie, 1913, pp. 111-114.

${ }^{11}$ A. Degert, "Albret (Pierre d')», en A. Baudrillart, A. Vogt y U. Rouziès, coords., Dictionnaire d'Histoire et de Géographie Ecclésiastiques, I, París, Letouzey et Ané, éditeurs, 1912, cols. 1730-1731; y "Albret (Pierre d')», en J. Balteau, M. Barroux y M. Prevost, coords., Dictionnaire de Biographie Française, I, París, París VI-Librairie Letouzey et Ané, 1933, col. 1322.
} 
Albret como un «hombre de ingenio peregrino y raro», un humanista de sólida formación en disciplinas muy diversas. Sin embargo, sus interpretaciones, como expondré posteriormente, conducirán a otras vías muy distintas.

El hecho de ser hijo natural del último rey de Navarra, Juan de Albret, procurará a Pedro de Navarra el acceso a una educación y a una formación intelectual en la que se encadenan su aprendizaje en el Estudio Municipal de Estella, formación que completaría con la disciplina de Gramática Latina en los monasterios de San Pedro de Cardeña y de Sahagún, tal como ha documentado recientemente J. Goñi Gaztambide. ${ }^{12}$ Su profesión como monje benedictino en el monasterio de Irache no le impediría, una vez terminado el noviciado y emitida la profesión religiosa, continuar sus estudios en los monasterios citados. Hacia 1540 debió abandonar la orden benedictina para pasar a ocuparse de asuntos que tocaban a los intereses de su estirpe nobiliar. Esta etapa, aún confusa y no bien documentada por sus biográfos, y que puede alcanzar hasta 1545, viene definida por tres circunstancias: su estancia en la corte del Emperador, en Valladolid; su participación en las academias próximas a la corte imperial, y el nacimiento de un hijo natural, Juan Basilio de Labrit y Navarra, al que debemos la conservación de alguna de las obras de su padre. Desde la «vertiente» francesa esta etapa es contemplada como una época en la que se dedicó a diversas negociaciones diplomáticas en las que lo empleó su hermano Enrique II en pro de los intereses dinásticos de la casa de Albret y de la restauración del Reino de Navarra. En esta dirección se inscribe su primera estancia en Roma en 1546; y, entre 1546 y 1555, sus frecuentes embajadas cerca del Emperador, por tierras de Flandes, en las que será empleado «oscurément», una vez muerto Enrique II, por Juana de Albret, cabeza visible de la corriente heréretica luterano-calvinista en el Sur de Francia, y su marido, Antonio de Borbón, príncipe de Vendôme. ${ }^{13} \mathrm{~A}$ ellos y a sus intereses dedicará su prolongada estancia en Roma, entre 1555-

\footnotetext{
${ }^{12}$ J. Goñi Gaztambide, «Pedro Labrit de Navarra, obispo de Comminges», Príncipe de Viana, 51 (1990), pp. 559-595 (la cita en pp. 559-560).

${ }^{13}$ Como soporte bibliográfico para el panorama histórico me he servido, fundamentalmente, de las obras o artículos de M. Menéndez Pelayo, Historia de los heterodoxos españoles [1880], I-II, Madrid, Biblioteca de Autores Cristianos, 19874; M. de Foronda y Aguilera, Estancias y Viajes del Emperador Carlos $V$ desde el día de su nacimiento hasta el de su muerte : comprobados... con documentos originales, relaciones auténticas... [1895], prólogo por D. Juan Pérez de Guzmán y Gallo, Madrid, Sucesores de Rivadeneyra, 1914; W. Walker, Jean Calvin, l'homme et l'oeuvre, Ginebra, A. Jullien, 1909; L. Romier, Les origines politiques des guerres de religion [1913-1914], I-II, Ginebra, Slatkine-Megaroitis, 1974; L.
} 
1558, y su actividad diplomática en torno al nuevo pontífice, Paulo IV, quien impone en Roma un régimen de «terrible severidad» del que da cuenta en los Diálogos de la diferencia del hablar al escrebir. Este estado de general prohibición es decisivo para que vuelva a Aquitania, donde esperaba encontrar descanso

Romier, Le royaume de Cathérine de Médicis. La France à la veille des guerres de religion [1922], I-II, Ginebra, Slatkine Reprints, 1978 [Contiene el vol. I del texto original: La France à la veille des guerres de religion, reimpr. de la edición de París de 1925]; L. Romier, Catholiques et huguenots à la cour de Charles IX. Les États Généraux d'Orléans. Le Colloque de Poissy. Le "Concordat» avec les protestants. Le massacre de Vassy (1560-1562), París, Perrin et $C^{\mathrm{ie}}$, Libraires-Éditeurs, 1924; J. Heritier, Catherine de Médicis, ed. rev. et corr, París, Fayard, 1942; J. Schorer, Jean Calvin et sa dictature, d'après des historiens anciens et modernes, Ginebra, P. E. Grivet, 1948; F. Braudel, El Mediterráneo y el mundo mediterráneo en la época de Felipe II, I-II, [1949], México, Fondo de Cultura Económica, 19932; J. R. Major, The Estates General of 1560, Princeton, Princeton University Press, 1951; R. M. Kingdom, Geneva and the coming of the wars of religion in France, 1555-1563, Ginebra, E. Droz, 1956; J. Delumeau, Vie économique et sociale de Rome dans la seconde moitié du XVI e siècle, I-II, París, E. de Boccard, 1957-1959; S. Mours, Le Protestantisme en France. 1. Au XVI e siècle, París, Librairie protestante, 1959; J. T. McNeill, The history and character of calvinism, I-III, Nueva York, Oxford University Press, 19623; C. Vivanti, Lotta politica e pace religiosa in Francia fra Cinque e Seicento, Torino, Einaudi, 1963;. E. Le Roy Ladourie, Les paysans de Languedoc, I-II, París, La Haya, Mouton, 1966; N. M. Sutherland, Catherine de Medici and the Ancient Régime, Londres, Historical Association, 1966; R. M. Kingdom, Geneva and the consolidation of the French protestant movement, 1564-1572, a contribution to the history of congregationalism, presbyterianism and calvinist resistance theory, Ginebra, E. Droz, 1967; N. L. Roelker, Queen of Navarre Jeanne d'Albret, 15281572, Cambridge, Belknap Press of Harvard University Press, 1968; G. Livet, Las guerras de religión. (1559-1598), Barcelona, Oikos-Tau, 1971; M. Yardeni, La conscience nationale en France pendant les guerres de religion (1559-1598), París, Faculté des Lettres et Sciences Humaines de Paris-Sorbonne, 1971 ; B. Bennassar y J. Jacquart, Le XVI e siècle, París, Armand Colin, 1972 [he manejado la edición española de B. Bennassar, J. Jacquart, F. Lebrun, M. Denis y N. Blayau, Historia Moderna, Madrid, Akal, 1980]; J. A. Maravall, Estado moderno y mentalidad social (siglos XV a XVII), I-II, Madrid, Revista de Occidente, 1972; Y. Cazaux, Jeanne d'Albret, París, A. Michel, 1973; J. Delumeau, El catolicismo de Lutero a Voltaire, Barcelona, Labor, 1973; H. Hauser, La prépondérance espagnole 1559-1660, París, Mouton, 19733; H. R. Williamson, Catherine de Médicis, París, Gérard Watelet, 1973; D. Nugent, Ecumenism in the age of the Reformation: the Colloquy of Poissy, Cambridge, Harvard University Press, 1974; H. Lapeyre, Las monarquías europeas del siglo XVI: las relaciones internacionales, Barcelona, Labor, 19793; J. C. Nieto, Juan de Valdés y los orígenes de la Reforma en España e Italia, Madrid, Fondo de Cultura Económica, 1979; P. Partner, Renaissance Rome 1500-1559: A portrait of a society, Berkeley, University of California Press, 1979; J. H. M. Salmon, Society in crisis, France in the sixteenth century, Londres, Methuen, 1979; R. García-Villoslada, «Felipe II y la Contrarreforma católica» y J. L. González Novalín, «La Inquisición española», en R. García-Villoslada, ed., Historia de la Iglesia en España, III, 2. ', La Iglesia en la España de los siglos XV y XVI, en J. L. González Novalín, Historia de la Iglesia en España. III-2. ${ }^{\circ}$ La Iglesia en la España de los siglos XV y XVI, en R. García-Villoslada, ed., Historia de la Iglesia en España, Madrid, Biblioteca de Autores Cristianos, 1980, pp. 5-106 y pp. 107-268; G. M. Monti, Ricerche su Papa Paolo IV Carafa: con 108 documenti inediti, Turín, Bottega d'Erasmo, 1980; N. M. Sutherland, The huguenot struggle for recognition, New Haven, Yale University Press, 1980; H. Jedin, Historia del Concilio de Trento, tomo IV, Tercer periodo. Volumen 1. Francia y la reanudación del Concilio, 1981; tomo IV, Tercer periodo, Volumen 2. Superación de la crisis, conclusión y ratificación, Pamplona, Universidad de Navarra, 1981; AA. VV., Arnaud de Salatte et son temps: le Béarns sous Jeanne d'Albre. Colloque International 
y libertad. Pero la situación es muy distinta: el panorama que le espera es el de la desolación de las guerras de religión, y la proliferación de «muchas especies de herejías fundadas en tiranidad e libertad para vicios». Encuentra así el escenario propicio para la composición de los Diálogos de la eternidad del ánima, en los que intenta refutar la herejía no a partir de la filosofía natural, de los santos doctores ni de la sagrada escritura, dado que los herejes rechazan estas autoridades, sino a partir de la razón natural. Estos diálogos, en una remitencia intertextual, son aquellos de los que se vale en los hasta ahora

d'Orthez, 16, 17 y 18 février, 1983, Orthez, Per Noste, 1984; J. H. Elliott, La Europa dividida. 1559-1598, Madrid, Siglo XXI, 19845; L. Febvre, A u coeur religieux du XVI siècle, París, Librairie Générale Française, 1984'; J. M. Maravall, Estudios de historia del pensamiento español. Serie segunda. La época del Renacimiento, Madrid, Ediciones Cultura Hispánica, 1984; I. Cloulas, Henri II, París, Fayard, 1985; J. Delumeau, La Reforma, Barcelona, Labor, 19854; M. Yardeni, Le refuge protestant, París , Presses Universitaires de France, 1985; E. Iserloh, J. Glazik y H. Jedin, Reforma protestante, reforma católica y contrarreforma, en H. Jedin, ed., Manual de historia de la Iglesia, V, Barcelona, Herder, 1986; J. A. Maravall, Antiguos y modernos. Visión de la historia e idea de progreso hasta el Renacimiento, Madrid, Alianza, 1986'; G. R. Elton, La Europa de la Reforma. 1517-1559, Madrid, Siglo XXI, 19876; J. Le Goff y R. Remond, eds., Histoire de la France religieuse, II, Du christianisme flamboyant a l'aube des Lumieres: (XIVe-XVIII ${ }^{e}$ siècle), París, Éditions du Seuil, 1988; E. G. Leonard, Histoire générale du protestantisme. 1, La Réformation, París, PUF, 1988; M. J. Rodríguez Salgado, The Changing Face of Empire. Charles V, Philip II and Habsburg Authority. 1551-1559, Cambridge, Cambridge University Press, 1988; S. C. Shannon, The political activity of François de Lorraine, duc de Guise (1559-1563), from military hero to Catholic leader, Ann Arbor, UMI, 1988; J. Lynch, España bajo los Austrias, 1. Imperio y absolutismo (1516-1598), Barcelona, Península, $1989^{6}$; G. R. Hale, Guerra y Sociedad en la Europa del Renacimiento. 1450-1620, Madrid, Ministerio de Defensa, 1990; J. R. Major, Society and institutions in early modern France, Athens, University of Georgia Press, 1991; C. Bost, Histoire des Protestants de France, Carrières-Sous, Poissy, Editions La Cause, 1992; H. A. Oberman, Lutero. Un hombre entre Dios y el diablo, Madrid, Alianza, 1992; H. Lutz, Reforma y Contrarreforma, Madrid, Alianza, 1994; R. MacKenneny, La Europa del siglo XVI. Expansión y conflicto, Madrid, Akal, 1996; B. Cottret, Calvin: biographie, París, Payot, 1998 [trad. del francés por T. Garin Sanz de Bremond, Calvino: la fuerza y la fragilidad, Madrid, Editorial Complutense, 2002]; M. Greengrass, The European Reformation, c. 1500-1618, London, Longman, 1998; F. Kermina, Jeanne d'Albret. La mère passionnée d'Henri IV, París, Perrin, 1998; J. Martínez Millán, ed., La corte de Felipe II, Madrid, Alianza, 1998; D. Bryson, Queen Jeanne and the Promised Land: dynasty, homeland, religion and violence in sixteenth-century France, Leiden, Brill, 1999; I. Cloulas, Catherine de Médicis: la passion du pouvoir, París, Tallandier, 1999; R. Teissier Du Cros, Jean Calvin: de la Réforme à la Révolution, París, Montreal (Québec), l'Harmattan, 1999; D. Crouzet, Jean Calvin: vies parallèles, París, Fayard, 2000 [trad. al castellano como Calvino, Barcelona, Ariel, 2001]; J. Lynch, Los Austrias: 1516-1700, Barcelona, Crítica, 2000; J. Pérez, Carlos V, Madrid, Temas de Hoy, 20003; J. Pérez, La España de Felipe II, Barcelona, Crítica, 2000; D. Müller, Jean Calvin: puissance de la Loi et limite du pouvoir, París, Michalon, 2001; J. I. Tellechea Idígoras, Paulo IV y Carlos V: la renuncia del imperio a debate, Madrid, Fundación Universitaria Española, 2001; B. Berdou D'Aas, Jeanne III d'Albret: chronique (1528-1572), Anglet, Atlantica, 2002; J. Garrison, Catherine de Médicis: l'impossible harmonie, París, Payot, 2002; M. Yardeni, Le refuge huguenot: assimilation et culture, París, Honoré Champion, 2002. 
considerados anónimos Diálogos de las herejías de Francia como base para difundir entre los nobles argumentos que frenen la expansión de la doctrina herética.

La firma del tratado de paz de Cateau-Cambrésis y la abdicación del Emperador en su hijo Felipe II diseñan una nueva coyuntura en la que Pedro de Navarra volverá a actuar de una forma que sigue despertando la polémica entre los que analizan su posición a favor de la restitución de la independencia del reino de Navarra, a la vez que no dejaba de lado sus intereses personales, como la reivindicación del priorato de Roncesvalles. Los pasos que seguirá en este proceso se traducirán en una primera negociación con Felipe II, en la que éste, sin ceder un ápice en lo concerniente a Navarra, llega a plantear la posibilidad de una «honesta recompensa» para Antonio de Borbón y Juana de Albret. Sin embargo, Felipe II expresará de forma explícita la profunda desconfianza hacia el supuesto papel de mediador imparcial con el que se presenta a sí mismo Pedro de Navarra, circunstancia que se agravará en el momento en que Catalina de Médicis pase a convertirse en la reina regente de Francia y posibilite la apertura de una vía para que se celebre un concilio nacional en el que se sienten todas las facciones religiosas en liza, desde católicos ultramontanos a calvinistas irreductibles, a fin de definir y asentar la separación del Estado del ámbito privado privado de la crencia y la práctica religiosas.

En junio de 1560 Felipe II pone fin a la misión diplomática de Pedro de Navarra en la corte española, sabedor ya de las conspiraciones que se vienen urdiendo en la Navarra francesa. Su posición no deja de ser delicada y mucho menos cuestionada: por una parte elabora un extenso informe dirigido al secretario de Estado Francisco de Eraso sobre la extensión de las herejías en Francia y el peligro que esto supone para la ortodoxia católica que Felipe II representa. Por otra, en Francia, tanto en la corte de Vendôme como en la de Catalina de Médicis, se sospecha que su frecuente correspondencia con Felipe II y su corte sea más que un indicio de su labor de espionaje. En esta tesitura, los reyes de Navarra le encomiendan una nueva misión, apoyados pasivamente por la regente Catalina: es enviado como embajador a Roma ante el nuevo papa Pío IV para jurar obediencia en su nombre en una audiencia especial que conllevaría de hecho, en caso de celebrarse, la aceptación por parte del papado de la legitimidad dinástica de Vendôme y Albret, y la independencia del reino de Navarra. La audiencia tiene lugar el 12 de diciembre de 1560 y el 
discurso ante la corte pontificia, limitado en su alcance por las presiones de la diplomacia española, le granjea las simpatías del Papa, quien le recompensará, poco después de su regreso a Bearn, otorgándole la diócesis de Cominges.

Entre junio y septiembre de 1563 asistirá a las sesiones del Concilio de Trento, que abandona antes de su conclusión. En carta a Catalina de Médicis justifica su decisión en el hecho de que no quería votar a favor de las medidas que los obispos de Francia proponían reglar contra la jurisdicción real o la primacía del derecho de los príncipes sobre el poder temporal de los obispos. A su vuelta, la ruptura con Juana de Albret se consuma: según las epístolas dirigidas a la corte española, por su radical oposición a la apostasía y la militancia herética de la reina; según los comentarios franceses y las actas de los juicios en los que se vio implicado, por intereses personales, por las regalías que ella le reclamaba y por haber acuñado moneda propia además de haber malversado fondos eclesiásticos.

Esta es una etapa en la que se pone directamente al servicio de Felipe II, manteniendo una correspondencia que, según Degert, «lui donne tout l'air d'un espion». Tras considerársele sospechoso de tramar junto a Blaise de Montluc un intento de liberar la Guyena, en manos de los reformistas, y tras ser condenado por el parlamento de Toulouse en 1565, y con una sentencia de embargo, Pedro de Albret abandona la Navarra francesa, renuncia al obispado, y se instala para bien morir en Estella, junto a sus hermanos, donde dicta testamento el 27 de agosto de 1567, la víspera de su muerte. C. Gutiérrez traza un bosquejo sumarizador de su vida:

Figura en su conjunto muy típica del Renacimiento, con sus contrastes de luces y de sombras, su pasión desmedida por las bellas artes, su cuidado del medro personal y sus vaivenes y bandazos en política; la cual, no obstante el ajetreo de tan pintoresca vida, supo mantener incólume a través de innúmeras vicisitudes y frente a halagos y amenazas la fe que había heredado de sus padres. Su preclaro ingenio y su esmero en el manejo de la pluma le dan un puesto de honor entre los cultos humanistas de aquella época brillante. ${ }^{14}$

La crítica francesa no suscribiría en estos términos las aserciones de C. Gutiérrez, y para ello, encuentra un sólido apoyo en la correspondencia

${ }^{14}$ C. Gutiérrez, Españoles en Trento, prólogo de J. Pérez Villanueva, Valladolid, CSIC, 1951, pp. 888895 (la cita en p. 894). Este volumen es el I del Corpus Tridentinum Hispanicum. 


\title{
mantenida entre el secretario de estado de su Santidad, Carlos Borromeo, y don Sebastián Gualtiero, obispo de Viterbo y Nuncio en Francia. ${ }^{15}$
}

\section{Testimonios manuscritos e impresos de la obra de Pedro de Navarra ${ }^{16}$}

\subsection{Testimonios manuscritos}

\author{
En la actualidad podemos documentar los siguientes testimonios \\ manuscritos:
}

${ }^{15}$ Podemos leerla en J. Šusta, op. cit., concretamente en el tomo I. También la encontraremos en H. Jedin, Krisis und Wendepunkt des Trienter Konzils (1562 / 63). Die neuentdeckten Geheimberichte des Bischofs Gualterio von Viterbo an den heiligen Karl Borromäus erstmals herausgegeben und gewürdigt, Würzburg, Rita-Verlag-Druckerei der Augustiner, 1941. Para la biografía de Pedro de Navarra deben considerarse como puntos de referencia obligados las obras de J. Goñi Gaztambide, Los navarros en el Concilio de Trento y la reforma tridentina en la diócesis de Pamplona, Pamplona, Imprenta Diocesana (Pampinolensia. Publicaciones del Seminario Diocesano de Pamplona, Serie A, vol. II) 1947, pp. 99132; y C. Gutiérrez, op. cit., pp. 888-895. Este volumen es el I del Corpus Tridentinum Hispanicum. J. Goñi Gaztambide, quien ya había adelantado algunas de sus aportaciones en «Los navarros en el Concilio de Trento", Revista Española de Teología, V (1945), 179-247, ya tuvo en cuenta los trabajos citados de A. Degert, cuya biografía de Pedro de Navarra es calificada por Goñi de «corta pero bastante exacta» (p. 99). Asimismo, Goñi tuvo en cuenta los trabajos de M. Arigita, D. Francisco de Navarra, Pamplona, 1899; y T. de Ascárate, «D. Pedro de Labrit, obispo de Comenges, a la luz de nuevos descubrimientos históricos», Boletín de la Comisión Monumental de Navarra, 11 (1920), 31-32 y 161-163, de cuyos datos biográficos opina que están «mezclados de errores» (p. 99). También J. Goñi Gaztambide trae a colación las obras, citadas anteriormente, de A. de Ruble y J. Šusta, de las que se nos señala que «aportan copiosos datos y documentos» (p. 99). El segundo autor mencionado, C. Gutiérrez, califica el estudio de J. Goñi Gaztambide como el «más completo y bien documentado» (p. 888) y parte de él para su bien informada tarea. Del trabajo de T. de Ascárate aduce que posee datos de interés. Del de J. Šusta, que «hay noticias importantes sobre su nombramiento episcopal y sus diversas embajadas a la Ciudad Eterna en 1560 y 1561» (p. 888); y del estudio de Ruble, «que contiene noticias de valor sobre las relaciones de Labrit con los duques de Vendôme» (p. 888). Todo este material le sirvió de base a P. M. Cátedra para el esbozo biográfico que traza sobre la figura de Pedro de Navarra, «Noticia de Pedro de Navarra» en su ed. de Pedro de Navarra, Diálogos de la differencia del hablar el escrevir, Bellaterra (Barcelona), «stelle dell'Orsa», 1985, pp. 11-57, donde se intentaba por primera vez establecer una convergencia entre su vida y su obra. Posteriormente nos encontramos con una nueva aportación de J. Goñi Gaztambide, «Pedro Labrit de Navarra, obispo de Comminges», ya citada, que completa y reexamina sus anteriores estudios, aportando una documentación inédita que viene a iluminar muchas de las lagunas que existían sobre la biografía del autor, y que podemos considerar sin lugar a dudas como punto de partida para todo estudio posterior. La nómina de los restantes autores a los que he tenido en cuenta en el esbozo biográfico, con las referencias completas de sus obras, puede documentarse en la revisión bibliográfica que acometo, seguidamente, en este artículo, con la excepción de A. Degert y J. Lestrade.

${ }^{16}$ Para una descripción catalográfica detallada de este punto, remito a la entrada «NAVARRA, PedRo DE», que he preparado para el proyecto, coordinado por P. Jauralde, del Diccionario Filológico de la Literatura Española. Siglos XVI-XVII, del que el volumen I, dedicado al siglo XVI, ya se encuentra en proceso de impresión (Madrid, Castalia). 
2.1.1.1. Dialogos de los grados de perfecion que ha de tener el Cortesano Eclesiastico, que pretende ser Cardenal // E de la institucion, e obligaciones desta dignidad, e de las buenas partes, que ha de auer el que a ella fuera elegido. E de la perfecion, e partes a que se obliga el Cardenal, que aspira a la Monarchia Eclesiastica. // Dictados por el muy jttre. señor dom Pedro Labrit de Nauarra, hijo del sermo Rey don juan de Nauarra. // Dirigidos al illmo e Rmo Don Giorgio de Armañac Obispo de Rodéz, è benemerito Cardenal su primo.

Contamos con el ejemplar de la Biblioteca Nacional de París, ms. Espagnol 368 / R 77654. 77 h. numeradas; portada en f. 1; f. 4 en blanco (250 mm x $202 \mathrm{~mm}$ ). Copia del siglo XVI. En el margen inferior del f. 1 se lee: «Ex Bibliotheca Mss. Coisliniana, olim Segurriana, quam Illustr. Henricus du Cambout, Dux de Coislin, Par Franciae; Episcopus Metensis, \&c. Monasterio S. Germani à Pratis legavit. An. M.DCC.XXXII».

Lo componen 12 diálogos, y los interlocutores son Fortunato y Basilio. Fue descrito someramente por A. Morel Fatio. ${ }^{17}$

2.1.1.2. Dialoggos de los grados de perfecion que a de tener el cortessano ecclesiastico que pretende ser Cardenal // e de la ynstitucion e obligaciones de esta dignidad e de las buenas partes q. a de aber el que a ella fuere elegido e de la perfecion e partes a que se obliga el Cardenal que aspira a la Monarchia ecclesiastica. // Dictados por el muy jllze señor don pedro labrit de Nauarra. Hijo del sermo rey don juan de Nauarra. // Dirigidos al jllmo et Rmodon Giorgio de Armañac. obispo de Rodes. E venemerito Cardenal Su primo.

Los conservamos en el ejemplar de la BNP, ms. Espagnol 248 / R 82593. 138 h. (200 mm x 140 mm). Copia del siglo XVI. Comienza: «Des mass. de M. Faure 144 // R. 8165. 2» [anotación manuscrita en margen inferior]. Se trata de un manuscrito muy esmerado en todos los detalles, a diferencia del anterior, como si fuera justamente el que pudiera haber sido el original sobre el que realizar una edición impresa. Basta comprobar la detallada tabla de contenidos. Hasta en las divisiones internas y en las marcas correspondientes se asemeja a lo que posteriormente encontraremos en la edición de los

${ }^{17}$ A. Morel-Fatio, Catalogue des manuscrits espagnols et des manuscrits portugais, París, Imprimerie Nationale, 1892, pp. 6-7, n. ${ }^{\circ} 25$. 
diálogos de Pedro de Navarra en Zaragoza. A. Morel-Fatio no prestó atención a este manuscrito, al describirlo sin más como un «autre exemplaire du même ouvrage» ${ }_{1}^{18}$ cuando éste es realmente el que debe servir como punto de partida para cualquier edición de la obra.

\subsubsection{Comentarios del cristianisimo rey de francia henrico $2 .^{\circ}$ deste nobre dictados por} el reberendisimo en xpo padre don pedro de labrit y navara obispo y conde de comeges hijo que fue del rey don Juan de labrít rei que fue de navara // dirigidos al excemo señor y gran dvque de florencia don [se deja en blanco el nombre] de medicis.

Contamos con el ejemplar de la BNE, ms. 2841 (olim I, 196): 6 h. sin paginar $+85 \mathrm{~h} . \times 3$ de guarda $(3+3) ; 205 \mathrm{~mm} \times 145 \mathrm{~mm}$ Copia del siglo XVII. Comienza: «D. Pedro de Labrit. Comentarios de Henrico 2. Rey de Francia» (f. [I]). Consta de siete «comentarios», subdivididos a su vez en un número no homogéneo de «libros». Descrito en el Inventario, IX, n. ${ }^{0} 2841,{ }^{19}$ pp. $14-15$ y en C. Gutiérrez. ${ }^{20}$

2.1.3. Dialogos del origen, autores, e cavsas de las eregías de francia e de la diversidad de sus herores e de las gveras, muertes, pestilencia, hambre e açotes con que dios los Ha Visitado.

Se conserva en la Biblioteca del Monasterio de San Lorenzo de El Escorial, ms. IV-b-30, 1 h. sin paginar +48 h. Comienza con: «Dialogos de las heregias de françia, desus auctores, causas y effectos...» [En la parte superior del folio, encima del título abreviado, aparecen dos signaturas, la primera tachada e ilegible; la segunda, «IV.b.30», corresponde a la que conserva en la actualidad; debajo del título, otra signatura, también tachada, en la que puede leerse «IV.c.18»] (f.s.n. [I]); «Carta del autor a quien dirige la obra. S. C. R. M.» [dirigida a Felipe II, nombrado como «R. MD»] (f. [1-2v]), al que siguen la portada y los doce diálogos que componen el manuscrito, con Cipriano y Basilio como interlocutores.

\footnotetext{
${ }^{18}$ Ibidem, p. 7, n. ${ }^{\circ} 26$.

${ }^{19}$ Inventario General de Manuscritos de la Biblioteca Nacional de Madrid, IX, Madrid, Servicio de Publicaciones de la Dirección General de Archivos y Bibliotecas - Ministerio de Educación Nacional, 1970, pp. 14-15, n. ${ }^{\circ}$ 2841, entrada «PEDRO DE NAVARRA, OBISPO DE COMEGES».

${ }^{20}$ Op. cit., p. 893.
} 
Estos diálogos han sido considerados como anónimos, en la línea de la habitual inercia del criterio de autoridad que tanto ha perjudicado la delimitación no solo del corpus sino también de la integridad como autor de Pedro de Navarra. Así figuraban en el catálogo de J. Gómez (1988), ${ }^{21}$ y así han seguido figurando en una monografía posterior (2000). ${ }^{22}$ Las investigaciones que llevé a cabo, enmarcadas en el proyecto general «El diálogo en el Siglo de Oro (Métodos e historia interna del género)», coordinado por Asunción Rallo Gruss entre los años 1995 y 1997, ${ }^{23}$ se encauzaron a demostrar cómo Pedro de Navarra reitera a lo largo de su obra, manuscrita e impresa, el hecho de haber escrito una serie de doce diálogos dedicados a «las diversidades de herejías y errores, e de los autores e causas que han sido y son en este miserable reino", refiriéndose a Francia (Diálogos de la eternidad del ánima). ${ }^{24}$

I. del Asso ya citaba literalmente ese pasaje de la dedicatoria a Paulo IV de sus Diálogos de la eternidad del ánima, en la que se refería a dichos diálogos sobre las herejías: "Contra los quales (los Hereges) yo he escrito doce Diálogos, dirigidos a V. Beatitud, donde leerá todas las adversidades de heregías, y errores de los auctores, y defensores, que han sido, y son en este miserable Reyno». ${ }^{25}$ Y, ya en un tiempo próximo, P. M. Cátedra ha avanzado una hipótesis que puede tener bastante más sustento del que se le suponía en el momento en que la enunció: «Otra obra suya menciona el propio autor en esa dedicatoria a Pío IV, doce diálogos sobre todas las diversidades de heregías

\footnotetext{
${ }^{21}$ J. Gómez, El dialógo en el Renacimiento español, Madrid, Cátedra, 1988, p. 220.

${ }^{22}$ J. Gómez, El diálogo renacentista, Madrid, Laberinto, 2000, p. 178.

${ }^{23} \mathrm{Vid}$., como fruto de ese proyecto de investigación, el volumen coordinado por A. Rallo Gruss y R. Malpartida Tirado, eds., Estudios sobre el diálogo renacentista español. Antología de la crítica, Málaga, Universidad de Málaga, 2006, en el que se recogen y traducen una serie de textos fundamentales para el estudio del diálogo renacentista, facilitando el acceso a algunos que ya eran de muy difícil acceso o lectura, mediante su traducción o su reedición: es el caso, particularmente, de los que se encuadran en el apartado I «Panorámicas (evolución, tipología, poética)», donde se recogen total o parcialmente aportaciones de G. Wyss Morigi, L. A. Murillo, E. Tierno Galván y L. Mulas, a lo que debe adjuntarse la selección bibliográfica, que consideramos imprescindible. Y, como complemento, compilación de una serie de estudios particulares sobre diversos diálogos bajo una rigurosa metodología de análisis, la monografía de A. Rallo Gruss, La escritura dialéctica. Estudios sobre el diálogo renacentista, Málaga, Universidad de Málaga, 1996, en la que recorreremos el ámbito de los diálogos áureos desde Alfonso de Valdés a Quevedo, pasando por fray Luis de León o Cristóbal de Villalón, Francisco de Osuna o Pedro de Luján.

${ }^{24}$ Pedro de Navarra, Diálogos de la eternidad del ánima, Tolosa, Jacobo Colomerio, s. a., f. 22. Cito por el ejemplar de la BNE R/5756.

${ }^{25}$ I. del Asso, op. cit., p. 88. Cita los Diálogos de la eternidad del ánima, f. 22.
} 
y errores e de los autores e defensores que an sido y son en este miserable Reyno, que no conservamos y quién sabe si don Pedro de Navarra incorporara a la última parte de sus Cenas sorianas, también perdida». ${ }^{26}$

\subsection{Testimonios impresos}

Para facilitar la tarea de identificación de los impresos, y teniendo en cuenta la confusión que se ha venido perpetuando desde el siglo XVII, atiendo a dos criterios simplificadores, pero evidentes tras una consulta de las múltiples referencias y catalogaciones bibliográficas:

- Los Diálogos de la diferencia del hablar al escrebir y los Diálogos de la eternidad del ánima sólo se imprimieron en Tolosa, en casa de Jacobo Colomerio, sin que se precise la fecha; aunque se encuentren junto a otros diálogos del mismo autor, por causas que atañen a la encuadernación, no existe documento alguno que nos permita presumir otra impresión distinta a la princeps. Sólo cabe la duda, suscitada por la anotación de Nicolás Antonio, sobre si existió una edición latina de los primeros, o sobre si circuló una edición en lengua toscana de los segundos. Hasta ahora, no hay documentación alguna que confirme esa suposición.

- Las series de diálogos que componen los de Cuál ha de ser el chronista del príncipe / De la diferencia que hay de la vida rústica a la noble / De la preparación de la muerte, se imprimen primeramente en Tolosa, en casa de Jacobo Colomerio, con una numeración consecutiva de los folios que la componen, $y$ he decidido, tal como consta en la portada del ejemplar de la BNE, R/5756, denominarlos Diálogos de varios asumtos. Todos ellos tienen una segunda edición en Zaragoza, en casa de Juan Millán, en 1567. Pero ello no obsta para que en algunas bibliotecas se le hayan añadido en la encuadernación, ocupando lo que correspondería a una portada «general» del volumen, la portada correspondiente de los Diálogos de la diferencia del hablar al escrebir o / y de los Diálogos de la eternidad del ánima, lo que ha generado un caos en

\footnotetext{
${ }^{26}$ P. M. Cátedra, loc. cit., p. 29. A esto debe unirse la «Carta de Pedro de Navarra a Felipe II (Nerac, 16 de septiembre de 1560, Archivo General de Simancas, Estado, 886, n. ${ }^{\circ} 170$ ), en la que informa con todo tipo de detalles a Francisco de Eraso sobre el estado de las herejías en Francia durante los últimos meses del reinado de Francisco II. Esta hipótesis que aquí avanzo se concretará en la edición que preparo de estos doce Diálogos sobre las herejías de Francia, en la colección «Autores Recuperados» de la Universidad de Málaga, junto a una, de más largo aliento, del corpus de Pedro de Navarra.
} 
la catalogación, sobre todo para aquellos que sólo se molestaron en ver la primera página sin atender al contenido del volumen completo.

2.2.1. Dialogos de la differencia del hablar al escrevir, (materia harto sotil y notable) dictados por el illustrissimo y Reuerendissimo Señor Don Pedro de Nauarra, Obispo ge de Comenge, y del consejo del Rey Christianissimo: Dirigidos al Illustrissimo Señor Don Luis de Beaumont, Condestable de Nauarra, Conde de Lerin, Ec., Tolosa: Iacobo Colomerio, Impressor de la Vniversidad, sin año.

Consta de cinco diálogos que tienen como interlocutores al Bastardo y al Duque. Contamos con la edición diplomática de D. O. Chambers del ejemplar de la Biblioteca de la RAE, R-/78; ${ }^{27}$ con la edición ya citada de P. M. Cátedra, (1985), en la que no consta el ejemplar que se ha seguido para realizar la edición; y de la traducción al inglés de D. P. Seniff, que marca un hito en la revalorización e interés que despierta Pedro de Navarra en ámbitos académicos ajenos al territorio español: «About the Differences There are Between Speaking and Writing», traducción al inglés de los Diálogos de la diferencia del hablar al escribir de Pedro de Navarra. ${ }^{28}$

2.2.2. Dialogos de la eternidad del anima, dirigidos al beatissimo padre Papa Pio Qvarto, de Casa de Medicis, dictados por el Illustrissimo y Reuerendissimo Señor Don Pedro de Nauarra, Obispo 9ede Comenge, y del Consejo del Rey Christianissimo, Tolosa: Iacobo Colomerio, Impresor de la Universidad, sin año.

Compone la edición una serie de nueve diálogos con Pedro y Latancio en el papel de interlocutores. No existe edición moderna, tal como ocurre con el resto de los diálogos del autor.

\footnotetext{
${ }^{27}$ Pedro de Navarra, Diálogos de la diferencia del hablar al escribir, [s. 1., Berkeley?], [s.i.], 1968.

${ }^{28}$ D. P. Seniff, «Ong, ramism and Spain: The case of Pedro de Navarra's Dialogues on the Differences between Speaking and Writing», en Bruce E. Gronbeck, Thomas J. Farrell, Paul A. Soukup, eds., Media, conciousness, and culture: Explorations of Walter Ong's thought, Newbury Park, California, Sage Publications, 1991, pp. 121-132. Téngase en cuenta la nota: «I omit the introductory "Letter of dedication" [imprescindible para entender el diálogo] and a few repetitious passages, shown by ellipses, but otherwises adhere closely to the original Spanish» [lo que quiere significar, una masacre del texto original y un aviso para navegantes de la filología española del Siglo de Oro]. Vid., además de las introducciones de D. O. Chambers, P. M. Cátedra y D. P. Seniff a sus ediciones o traducción, el ensayo de E. L. Rivers, «Lo escrito y lo oral: don Pedro de Navarra», en L. Schwartz Lerner e I. Lerner, Homenaje a Ana María Barrenechea, Madrid, Castalia, 1984, pp. 307-311.
} 
2.2.3. Dialogos de Barios Asumtos. En Tolosa Año de 1560. Por D.n Pedro De Nauarra Obispo de Comenge, sin indicación del impresor.

Corresponden al ejemplar de la BNM R/5756. Va encabezado, con foliación independiente para cada uno de ellos, por los Diálogos de la eternidad del ánima y por los Diálogos de la diferencia del hablar al escrebir, tal como se editaron en casa de Jacobo Colomerio, y a continuación figuran tres series de diálogos que algunos estudiosos pasaron por alto al no examinar a fondo el impreso, con numeración consecutiva de los folios:

2.2.3.1. Diálogos qual debe ser el chronista del principe materia de pocos aun tocada, Dirigidos al católico Rey de España Don Phelipe de Austria segundo deste nombre. Dictados por el illustrissimo Reuerendissimo Señor Don Pedro de Nauarra (por la gracia de Dios) Obispo de Comenge, del Consejo del Christianissimo Rey de Francia.

Cuatro diálogos entre los interlocutores Cipriano y Basilio.

2.2.3.2. Dialogos de la diferencia que ay de la vida rustica a la noble (Doctrina muy vtil para los errores de nuestros tiempos) Dictados por el illustrissimo Reuerendissimo Señor Don Pedro de Nauarra (por la gracia de Dios) Obispo de Comenge del consejo del Christianissimo Rey de Francia. Dirigidos al Marques de Mondejar, Presidente del consejo supremo de Castilla.

Serie de cuatro diálogos entre un Noble y un Rústico.

2.2.3.3. Dialogos de la preparacion de la mverte, dictados por el Illustrissimo Reuerendissimo Señor Do[n] Pedro de Nauarra Obispo 9e de Comenge y del consejo supremo del Christianissimo Rey de Francia, Dirigidos al muy magnifico señor Fra[n]cisco de Erasso primer secretario y del consejo secreto del Rey Catolico de España.

Compuestos por una serie de treinta y un diálogos con Cipriano, Basilio y la Muerte como interlocutores.

2.2.4. Dialogos muy subtiles y notables, hechos por el illvstrissimo y Reuerendissimo señor Don Pedro de Nauarra, Obispo de Come[n]ge. Van dirigidos al muy Catholico Rey de España don Phelippe nuestro Señor, Zaragoza, Juan Millán en la Cuchillería, 1567.

En este volumen se recogen las tres series de diálogos que hemos numerado desde el 2.2.3.1. al 2.2.3.3. (Cuál ha de ser el chronista del príncipe / De la diferencia que hay de la vida rústica a la noble / De la preparación de la muerte), 
sin variantes de consideración entre ellos, a primera vista. La anotación de J. M. Sánchez no deja de ser pertinente:

No son raros los ejemplares de esta impresión zaragozana: los hay en la biblioteca nacional de Madrid, en el British Museum, y otro guardo yo en mi librería. Lo que no suele ser frecuente es hallarlos en buen estado y completos, porque casi todos ellos han sido expurgados por la Inquisición. De este libro existe una edición hecha en Tolosa de Francia, anterior a la de Zaragoza y de la cual Salvá poseyó un ejemplar: carece de año y de nombre de tipógrafo; pues aunque Nicolás Antonio afirma que el impresor fue Jacobo Colomer, es lo cierto que en ella no se lee este nombre. ${ }^{29}$

\subsection{Otros testimonios.}

Aquí tienen cabida las obras que hoy se dan por perdidas y de las que el autor dio testimonio de haber escrito:

Afortunadamente, los doce diálogos que dedicó al origen, causas y autores de las herejías que proliferaron en el sur de Francia ya han podido ser recuperados, pero nos queda una serie de obras de las que hace mención en una carta dirigida al Duque de Villahermosa, fechada a 9 de octubre de 1565, ${ }^{30}$ desde una perspectiva en la que el ejercicio de la vida pública, la del cortesano renacentista, da paso a la «singular vista, riberas, aire, cielo y campania con solo fin de soledad y estudio», en una prefiguración del neosenequismo que se nos sobrevendrá desde muy distintas lecturas en el siglo XVII. ${ }^{31}$ Pedro de Navarra afirma haber escrito «doce cenas de su renombre, llamadas las Cenas sorianas, porque la viña se llama Santa Soria, que las seis dellas tratan de toda la philosophia natural y del ser, virtud e operación de todo lo criado so el cielo, simple y compuesto con raros secretos y virtudes de la natura y de los efectos perdidos e imperfectos dellas... E las otras seis tratan del origen, medios y

\footnotetext{
${ }^{29}$ J. M. Sánchez, Bibliografía aragonesa del siglo XVI, II, Madrid, Imprenta Clásica Española, 1914, pp. 160-161.

${ }^{30}$ «Carta de Pedro de Navarra al Duque de Villahermosa (Viella, 9 de octubre de 1565)», en Duque de Alba y Berwick, Noticias históricas y genealógicas de los Estados de Montijo y Teba, según los documentos de sus archivos, Madrid, 1915, Carta CXLIII, pp. 321-322.

${ }^{31}$ La aquilatación del motivo en el siglo xvi ya ha sido objeto de estudio en A. Rallo Gruss, El menosprecio del mundo. Aspectos de un tópico renacentista, Málaga, Universidad de Málaga, 2004, especialmente en el apartado I «El mundo y su configuración moral: el mundo inmundo», y en los dos primeros subapartados del II «La fortuna: tópicos y variantes de la paradoja del mundo».
} 
fines de todas las leyes, religiones, sectas buenas y malas desde el principio del mundo hasta nuestro tiempo, que no se dirá estéril de horrores». ${ }^{32}$

Además de estas Cenas sorianas, da cuenta a su interlocutor de su trabajo en otra obra que, hasta ahora, consideramos perdida: el Trium foeminarum, obra en la que las mujeres que han llevado al catolicismo a su perdición en las sectas heréticas se ejemplificarían en las figuras de mujeres contemporáneas que ejercieron el poder en contra del catolicismo, especialmente la reina Juana de Albret, madre del futuro rey de Francia Enrique IV.

Queda, por último su amplio, extenso y casi inabarcable espistolario, dirigido no sólo a su amigos, sino, lo que más polémica podría provocar, también, y de forma simultánea, a la corte de Felipe II y a la regente del trono francés, Catalina de Médicis. La lectura de algunas de esas cartas, que pueden configurarse como epístolas, confesiones, delaciones, informes, o simples anales de hechos desde la perspectiva más conveniente, exige una labor de investigación que sobrepasa con mucho los límites de esta aportación. Se trata de un terreno virgen, abierto a perspectivas en las que el investigador podrá descubrir a un autor que da una visión de sí mismo y de sus circunstancias que, en cierto modo, nos ayudaría a componer la fragmentaria panorámica que de él nos ha sido legada.

\section{ESTADO DE LA CUESTIÓN Y PRECISIONES}

\subsection{Estado de la cuestión}

La edición de los diálogos impresos de Pedro de Navarra no presenta problemas de hondo calado. Como ya apunté anteriormente, los Diálogos de la diferencia del hablar al escrebir y los Diálogos de la eternidad del ánima, en todos los casos, corresponden a la impresión que sin fecha se realizó en Tolosa, en casa de Jacobo Colomerio. Y ese es el único testimonio válido para cualquier impresión posterior. Sí reclaman una edición crítica las series Cuál debe ser el chronista del príncipe, De la diferencia que hay de la vida rústica a la noble y De la preparación de la muerte, en la que se anoten y busquen las variantes entre la impresión de los que he denominado Diálogos de varios asumtos, correspondientes al ejemplar de la BNE, R/5756, procedentes también de Tolosa, en la imprenta de Jacobo

\footnotetext{
32 «Carta de Pedro de Navarra al Duque de Villahermosa (Viella, 9 de octubre de 1565)», p. 322.
} 
Colomerio, y su posterior edición en Zaragoza, bajo el título de Diálogos muy subtiles y notables, por Juan Millán, en 1567, en las que quedan integradas dichas series de diálogos. Hasta ahora sólo contamos con dos ediciones, y ambas corresponden al diálogo que la crítica y la historiografía literaria han concedido en otorgar un lugar privilegiado: los Diálogos de la diferencia del hablar al escrebir, dado el interés que despiertan entre las más diversas escuelas representativas del estudio de la lingüística general, de la retórica, y de disciplinas afines: ${ }^{33}$ por una parte la edición diplomática de D. O. Chambers, por otra la de P. M. Cátedra, que abría cauces hasta entonces inéditos a una caracterización integral de la figura de Pedro de Navarra; y, por último, la traducción al inglés, ya mencionada, de D. P. Seniff. El resto de sus diálogos impresos han caído en el olvido editorial, excepto algunos fragmentos que puntualmente han venido rescatando autores que, más que a la disciplina de la filología, pertenecen al ámbito de la historiografía de la historia, de la sociología, y de campos afines, con una especial mención a los tempranos estudios de S. Montero Díaz, ${ }^{34}$ a las citas frecuentes de J. A. Maravall en su amplia trayectoria investigadora, ${ }^{35} \mathrm{y}$ a otros autores más recientes. ${ }^{36}$

En los estudios filológicos sus obras han servido para fundamentar construcciones teóricas y argumentaciones tan distantes como las que

\footnotetext{
${ }^{33}$ Vid. Seminar of Spanish Renaissance Rhetoric de la Universidad de Michigan, «Data FormatBibliography. Section "Hispanic Rhetoric"», Dispositio: Revista hispánica de semiótica literaria, 22-23, 8 (1983), pp. 19-64, esp. p. 31.

${ }^{34}$ S. Montero Díaz, «Estudio preliminar. La doctrina de la historia en los tratadistas del Siglo de Oro» en Luis Cabrera de Córdoba, De historia para entenderla y escribirla (1611), Madrid, Cosano Imp., 1948, pp. v-LVII; y «La doctrina de la historia en los tratadistas españoles del Siglo de Oro», Hispania, I (1941), pp. 3-39.

35 J. A. Maravall, «Sobre naturaleza e historia en el Humanismo español», Arbor, 64 (abril de 1951), pp. 469-493, reimpr. en AA.VV., Historia de España. Estudios publicados en la revista «Arbor», Madrid, Pueyo, 1953; Estado moderno y mentalidad social (siglos XV a XVII), I-II, Madrid, Revista de Occidente, 1972; «La concepción del saber en una sociedad tradicional», Estudios de historia del pensamiento español. Serie primera. Edad Media, Madrid, 1973², pp. 215-272; «La diversificación de modelos de Renacimiento: el Renacimiento español y el Renacimiento francés», Estudios de historia del pensamiento español. Serie segunda. La época del Renacimiento, Madrid, Ediciones Cultura Hispánica, 1984, pp. 123-192; Antiguos y modernos. Visión de la historia e idea de progreso hasta el Renacimiento, Madrid, Alianza, 1986².

${ }^{36}$ Vid., entre otros, AA. VV., «Albret, Pedro de» en Gran Enciclopedia Navarra, I, Pamplona, Caja de Ahorros de Navarra, 1990, p. 200; G. R. Hale, Guerra y Sociedad en la Europa del Renacimiento. 1450-1620, Madrid, Ministerio de Defensa, 1990; F. Bouza Álvarez, «Corte es decepción. Don Juan de Silva, conde de Portalegre», en J. Martínez Millán, ed., La corte de Felipe II, Madrid, Alianza, 1996, pp. 451-502; C. J. de Carlos Morales, «El poder de los secretarios reales: Francisco de Eraso», en ibidem, pp. 107-148.
} 
conforman el entramado de las monografías de J. Ferreras ${ }^{37}$ y las de J. Gómez. ${ }^{38}$ Pero nuevamente sólo funcionan como «apoyaturas» para un constructo teórico, sin atender a la coherencia y relevancia textuales que impone la complejidad del «yo-autor-humanista» de Pedro de Navarra. E. L. Rivers (1984), P. M. Cátedra (1985) y D. P. Seniff (1991) sí han percibido la «modernidad» latente en la diferencia que Pedro de Navarra establece entre lo escrito y lo oral desde la vertiente del «lenguaje» considerado como ámbito autónomo, que debe ser corregido, reprimido, manipulado o moldeado en función de unas premisas y circunstancias socioculturales y políticas determinadas y concretas, tal como ya lo precisara P. M. Cátedra. La imbricación del autor navarro en el ramismo y en la trayectoria del pensamiento de Walter Ong debe esperar por ahora acordes parecidos a los que Noam Chomsky dedicaba al Examen de ingenios de Huarte de San Juan o Lore Terracini a la lengua en el siglo XVI. ${ }^{39}$

En lo que concierne a sus manuscritos, ninguno de ellos ha suscitado el interés de una edición modernizada. Los Diálogos de los grados de perfección que ha de tener el Cortesano Eclesiástico, con dos manuscritos muy distintos en la Biblioteca Nacional de París, e inscritos en las discusiones académicas que F. A. Yates documenta con un rigor minucioso, ${ }^{40}$ pasan desapercibidos y malinterpretados en el catálogo ya mencionado de A. Morel-Fatio, aun cuando sus implicaciones relativas a cuestiones que se abordarían, no muy pacíficamente, en las últimas sesiones del Concilio de Trento, puedan convertirse en un acicate, en vez de un escollo, por el que aún no se han arriesgado ciertos historiadores de la espiritualidad europea de los siglos XVI y XVII. ${ }^{41}$ Sus Comentarios de cristianíssimo rey de Francia Henrico 2. ${ }^{a}$, manuscrito fragmentario copiado por su hijo natural, Juan Basilio de Labrit, ciertamente ignorado casi por todos sus estudiosos, aporta muchas pruebas a favor de lo que he venido en denominar la «vertiente francesa» de la historiografía sobre Pedro de Navarra. Su posición, no en vano, se mantiene más cerca de

\footnotetext{
${ }^{37} \mathrm{~J}$. Ferreras, Les dialogues espagnols du XVI e siècle ou l'expression littéraire d'une nouvelle conscience, I-II, París, Didier, 1985; versión española: Los diálogos humanísticos en lengua castellana, Murcia, Universidad de Murcia, 2003.

${ }^{38} \mathrm{Vid}$. las referencias en notas anteriores.

${ }^{39}$ N. Chomsky, El lenguaje y el entendimiento, Barcelona, Seix Barral, 1974, pp. 28-31; L. Terracini, Lingua come problema nella letteratura spagnola del Cinquecentto, Turín, Stampatori, 1979.

${ }^{40}$ F. A. Yates, The French Academies of the Sixteenth Century, Londres - Nueva York, Routledge, 1988.

${ }^{41}$ No debe extrañarnos que no figure alusión alguna ni a su persona ni a su obra en M. Bataillon, Erasmo y España. Estudios sobre la historia espiritual del siglo XVI, México, Fondo de Cultura Económica, $1966^{2}$.
} 
la apología a Enrique II y de su ayuda a las facciones protestantes que a los móviles «imperiales» de Carlos V, y el panorama que presenta de las diferentes campañas, a modo de anales, le compromete seriamente con una causa que presumiblemente no se corresponde con aquella que la historiografía española le ha atribuido. Y es una lacra para la filología que quiera presumir de cierta «heterodoxia» el que aún permanezcan inéditos, aunque presenten marcadas dificultades de transcripción, en los anaqueles de la BNE.

Nos restan los hasta ahora considerados anónimos doce Diálogos sobre las herejías de Francia, sobre los que creo poseer datos ya más que suficientes como para demostrar que son los mismos a los que se refiere en reiteraradas ocasiones el propio Pedro de Navarra y que han sido objeto de estudio, para ejemplificar determinadas hipótesis, en trabajos de carácter monográfico sobre el diálogo en el renacimiento español. El manuscrito de la Biblioteca del Monasterio de San Lorenzo de El Escorial presenta algunas dificultades de lecturas en lo que concierne a la transcripción de los nombres propios. El resto es perfectamente legible, a pesar de estar copiado ya en letra bastarda propia del siglo XVII. Sólo J. Gómez se ha referido a estos diálogos anónimos y los ha incluido en su catálogo final. ${ }^{42}$

\subsection{Precisiones}

De todo lo expuesto se desprenden una serie de consecuentes que deberán ser tenidos en cuenta para cualquier estudio ulterior:

a) La escasa bibliografía con la que hasta ahora contamos sobre un humanista cuyo papel relevante en una cuestión que, aún hoy, sigue teniendo vigencia, como todo lo que atañe a la restitución de la independencia del reino de Navarra y sus relaciones con las monarquías española y francesa, debería servir de acicate para paliar esa penuria, que no se corresponde con la atención que a su figura se le prestó ya en el siglo XVI, y posteriormente, en los siglos XVI y XVII.

b) La escasa bibliografía con la que contamos suele atender más a la posición política del autor, en su condición de agente al servicio, bien de los reyes de Navarra bien de los de España (Carlos V y Felipe II), bien de los de

\footnotetext{
${ }^{42}$ Vid. los estudios citados del autor, correspondientes a los años 1988 y 2000, p. 220, n. ${ }^{\circ} 43$ y p. 178, respectivamente.
} 
Francia (su elogio de Enrique II y su correspondencia con Catalina de Médicis así lo muestran), más que a su obra.

c) El hecho de que se haya forjado una imagen arquetípica del autor a través de los tratamientos que los historiadores han prestado a su figura desde el siglo XVI. Podemos atender a un proceso por el que una serie de ideas $\mathrm{u}$ observaciones iniciales sobre su figura, y un conjunto de juicios, más o menos precipitados o superficiales, se convierten en tópicos que se han venido repitiendo hasta la saciedad, sin contrastar su validez con la propia obra del autor, que por otra parte, nos dará de sí una panorámica muy distinta según se atienda a los diálogos que decidió imprimir, o a obras manuscritas inéditas como los comentarios sobre Enrique II o su corpus epistolar.

d) La necesaria atención que debería prestarse a su figura como prototipo de «humanista» del renacimiento español, siempre teniendo en cuenta la particularidad de que su ascendencia genealógica, la de ser bastardo del último rey de la Navarra independiente, lo imbrica en una corriente cultural en la que convergen, por una parte, su ligazón con el reino de Francia y, por otra, la que tiene con el reino español.

Todo esto aboca a un imperativo filológico: la necesidad de que se revise la bibliografía y la tópica que se ha venido acumulando en torno al autor para deslindar:

a) lo que es notoriamente falso

b) lo que es una repetición tópica, sin contrastar con la realidad del texto.

c) lo que son aportaciones significativas que han intentado conformar una imagen individualizada del autor en correspondencia con sus textos.

Y es esto lo que me propongo llevar a cabo al atender a la bibliografía repertoriada sobre Pedro de Navarra en el siglo xvIII. Dejo para un proxímo artículo la revisión de la bibliografía del siglo XIX, que me permitirá ahondar en estos factores que he enumerado y que, hasta su culminación en el estudio de I. del Asso, a fines del XVIII, sientan las bases de toda una serie de inercias, repeticiones y malentendidos posteriores. ${ }^{43}$

\footnotetext{
${ }^{43}$ En este proceder tendré en cuenta en todo momento las páginas más esclarecedoras sobre la evolución de la historiografía literaria española, siguiendo un proceso de deconstrucción de todos los elementos que la han ido lastrando hasta conducirla a un estado de postración y anquilosamiento, debidas como apunta J. Lara Garrido, «Historia y concepto (sentido y pertinencia del marbete Siglo de Oro)», Del
} 


\section{BibliografíA REPERTORIADA DE LOS SIGLOS XVII Y XVIII.}

\subsection{Antecedentes. Siglo XVI.}

Podemos considerar como antecedentes del primer tratamiento más cercano a Pedro de Navarra a una serie heterogénea de autores por distintas circunstancias.

\subsubsection{Muret (1560)}

En primer lugar a M. A. Muret, ya que en sus obras podemos leer el discurso de Pedro de Navarra ante el consistorio papal pronunciado en diciembre de 1560, al que nos hemos referido anteriormente. ${ }^{44}$

Siglo de Oro (métodos y relecciones), Madrid, Universidad Europea / CEEs Ediciones, 1997, pp. 23-56, que deben completarse con su introducción a E. Orozco Díaz, La literatura en Andalucía (De Nebrija a Ganivet), edición, introducción y anotaciones de J. Lara Garrido, Málaga, Universidad de Málaga, 2007. La introducción, que lleva por título «Sobre la "Historia de la literatura en Andalucía"». Materiales y reflexiones», pp. 11-52, discurre por unos derroteros mucho más amplios que los que ese título lleva a suponer, pues su análisis de los intersticios de la crisis de la historia literaria tradicional (o nacional), su examen de las limitaciones originarias de la literatura nacional como objeto de conocimiento, del carácter retardatario de la perspectiva regional, con una serie de anotaciones a partir de la recepción de la obra bibliográfica de Nicolás Antonio, que culmina en la propuesta de un encuadre y razones que posibiliten una práctica historiográfica renovadora, se convierten en inexcusable punto de partida para los caminos por los que debería peregrinar el futuro de la filología española.

${ }_{44}^{44}$. Antonii Muret, Opera omnia, I, édit. Runkenius, Lugduni Batavorum, 1789, pp. 51-59. De todo este proceso nos da testimonio una carta del embajador de Francia, fechada el 5 de diciembre de 1560 y dirigida al monarca francés, en la que se nos da cuenta de la audiencia del Papa a Pedro de Navarra, de la encendida defensa que éste hizo del catolicismo de los reyes de Navarra, de la buena impresión que causó en el Papa, la buena «grace et façon» con que se expresó en lengua española y de la favorable actitud del Papa para conceder la recepción a los reyes de Navarra aun teniendo graves sospechas de las contrariedades que esto conllevaría. La carta la reproduce A. Galland, Mémoires pour l'histoire de la Navarre et de Flandre, contenants le droit du roy au royaume de Navarre..., París, Mathieu Guillemot, 1618, pp. 91-92. A pesar de los maniobras de la diplomacia española para interferir y obstaculizar la misión encomendada a Pedro de Navarra, el consistorio se celebró en la fecha y el modo previstos, es decir, el 14 de diciembre de 1560 en la Sala Regia, y en él, Pedro de Navarra rindió homenaje al Pontífice en nombre del rey de Navarra, pronunciando en latín «un brillante discurso que había sido preparado por el famoso humanista Marco Antonio Mureto. Contestóle, en nombre de la Curia Romana, el canciller del Papa, Frorebellius. Del acto se formó un proceso verbal, que fue firmado por todos los cardenales. Desde aquel momento el Rey de Navarra fue equiparado en la Cancillería Pontificia a los otros soberanos», según J. Goñi, op. cit., p. 104. A. de Ruble, op. cit., pp. 45-46, describe esta sesión en los siguientes términos: nos dice cómo el 14 de diciembre los dos embajadores se presentaron y don Pedro «prononça une harangue d'apparat en latin, qui avait été écrite par le célèbre humaniste» Marc-Antoine Muret. El canciller del Papa, Florebellius, respondió 


\subsubsection{Testimonios sobre su participación en el Concilio de Trento (1563).}

En segundo lugar habría que atender a los testimonios, no escasos y contradictorios y confusos, sobre su asistencia a las sesiones finales del Concilio de Trento, dadas las divergencias existentes entre las actas oficiales y los testimonios personales del propio Pedro de Navarra, a través de su correspondencia. No prestaría demasiada atención a esta circunstancia de no ser porque en los Diálogos de las herejías de Francia se enfrentan las posiciones de un obispo y un noble, que se encuentran fortuitamente: el obispo, Cipriano, se dispone a emprender el viaje por mar hacia el Concilio y el noble, Basilio, alardea de su adhesión a las doctrinas heréticas que han encontrado un firme cimiento en la región de Aquitania y la Navarra francesa.

Tras las diversas hipótesis que se han barajado, entre las que se llegó a la de que asistió a las sesiones de Trento en dos ocasiones, las últimas investigaciones, documentadas por Goñi, y ya apuntadas por C. Gutiérrez, testimonian que «su arribo - el único que hizo - a Trento no debió tener lugar hasta fin de junio del 63, esto es pocos meses antes de clausurarse la asamblea. Esto explicaría que hasta dicho tiempo no se acuse su presencia entre los Padres», para lo que remite a Jedin, quien reproduce un despacho de Gualterio relativo a esta circunstancia fechado a 4 de julio $1563 .{ }^{45}$

Con fecha de 12 de julio de 1563 las actas del Concilio informan de que prometió entregar su voto de reforma al secretario. Tres días más tardes aparece como uno de los asistentes aquel día a la sesión vigésimo tercera. Son éstas las únicas dos veces en las que le menciona el encargado de las actas , Massarelli. ${ }^{46}$

\footnotetext{
en nombre de la corte romana, y un proceso verbal, firmado por todos los cardenales, «certifia les honneurs rendus au représentant de la maison d'Albret». Según A. de Ruble, el discurso de Muret, «qui est conçu dans le sens catholique le plus pur, fut plus tard désavoué par le roi de Navarre». A pesar de estos inconvenientes, a los que se añaden los desacuerdos sobre la autoría del discurso, ya que algunos lo atribuyen directamente a Pedro de Navarra y no a Muret, la misión de Pedro de Albret constituyó un éxito y, como escribe A. de Ruble, «fut peu connue en France et la popularité d'Antoine dans le parti huguenot n'en fut pas atteinte: ses amis présentaient ses démarches à Rome comme une manoeuvre anti-espagnole. Les agents anglais signalaient malignement son succès». Por el contrario, Chantonay «observait à son maître que la condescendance de Pie IV aurait de graves conséquences sur les négociations futures du roi de Navarre».

${ }^{45}$ J. Goñi, op. cit., p. 891, y H. Jedin, Krisis und Wendepunkt des Trienter Konzils (1562 / 63), p. 265.

${ }^{46}$ Concilium Tridentinum. Diariorum, Actorum, epistolarum, tractatuum nova collectio, Ix, Friburgo de Brisgovia, Herder, $1966^{2}, 615,18 ; 637,37$.
} 
A fines de septiembre de 1563 podemos considerar como hecho probado su decisión de abandonar Trento, sin entrar en matices por ahora, ya que por una parte, pesarían en la balanza de la configuración de ese «modelo» que conocemos como Pedro de Navarra sus cartas a la regente Catalina de Médicis, y, por otra, las cartas que recientemente Goñi Gaztambide ha dado a luz, dirigidas a sus familiares más directos en Navarra, en las que esgrime razones muy otras a las que expone a la regente francesa para abandonar Trento. C. Gutiérrez concluye que «un catálogo de asistentes al Concilio salido a la luz en Brescia el 15.9.1563 no le cuenta entre los conciliares; por más que otro que juzgo posterior, publicado también en Brescia, le registra en estos términos (hoja [3. $\left.\left.{ }^{\mathrm{a}}\right]\right):$ Petrus Allebret, nauvarrus episc. Cumenensis [sic]. En todo caso, es cierto, que entre los prelados que suscribieron los decretos al final de la asamblea no aparece su nombre; lo que indica que no estaba en el Concilio». ${ }^{47}$

\footnotetext{
${ }^{47}$ C. Gutiérrez, op. cit., p. 891. En J. Goñ, loc. cit., los ámbitos político, religioso y personal quedan perfectamente entrelazados y explican razonablemente la posición «absentista» de Pedro de Navarra hacia las declaraciones finales de Trento: «El 16 de febrero de 1563 escribía desde la capital de su diócesis, Saint-Bertrand, al duque de Villahermosa: "A nosotros los obispos nos tornan a mandar ir al Concilio, en el cual, lo que se ha hecho ya, lo envío a V. S. estampado. Temo que no me podré librar desta jornada"». Sus temores se cumplieron. El 27 marzo 1563 se hallaba en Viella, valle de Arán; pero el 18 de junio se encontraba ya en Trento, al menos de cuerpo presente. Su espíritu había volado muy lejos, como se desprende de la carta que en la referida fecha escribió a su sobrino Miguel de Gabiría: “Virtuoso sobrino: Tres o cuatro veces te he escrito e tú jamás me has respondido. Recibiré muy gran servicio que solicites a esos señores que en todo caso yo halle acabadas las herrerías para el principio de setiembre, que seré allá, e que no haya falta. E mira que halle guardado todo el hierro que se hiciere, que no se venda nada, e que te des también recado en todo como yo te tengo mandado; si no, cree que yo te pagaré como tú obrarás. Aquí se te han comprado muy buenos vestidos, que te llevaré. Por ende hace tu deber y créeme no te diré, que sea Dios contigo. De Trento a 18 de junio. Tu tío y señor don Pedro de Navarra. Encomiéndame a mastre Peirotet, a sus hijos e a mastre Juan y su hermano, e a los maestros vizcaínos, y ruégales de mi parte que trabajen tanto, que no falte por ellos e que yo les daré cabuenas estrenas en allegando. Tu primo es tan bellaco como nunca. Yo lo he bien vestido y quería lo dexare soldado en Milán y lo había hablado al virrey, pero él es tan gran traidor, que no sólo no ha querido servir, pero ha dado un bofetón a Montaut, el cual es otro tal como él. Yo les despedí y le di a Pedro 6 escudos e al otro ocho. Si allá fieren y sé que tú le recogieres ni favorecieres en un clavo, jamás habrás de mí un real en fe de cristiano". Indudablemente se sentía más conde que obispo. El 4 de julio de 1563 Viterbo escribía a Borromeo: "Cuando el obispo de Comminges me buscó otra vez para que hiciera el oficio de que di aviso estos días pasados, me pareció bien dar cuenta de él a Mons. Illmo. Granvela". Se ingnora en qué consistía la diligencia a que alude Viterbo, pero desde luego era muy importante. Mientras recibía la contestación de Roma, Viterbo tenía intención de nutrir en don Pedro la esperanza de obtener la conversión de la reina doña Juana. Al parecer, el obispo de Comminges no se forjaba muchas ilusiones sobre este particular. El 16 de febrero de 1563,
} 
De la lectura aportada por la documentación adjuntada por J. Goñi se desprende la imagen de un Pedro de Navarra que cumple con ese precepto del cortesano humanista en el que la vida privada y la introspección en una relación interactiva con la dimensión exterior del ámbito de lo público, del interés político y material, conforman lo que será la substancia del yo que se anuncia como preámbulo de la modernidad. En definitiva, el formare humanístico carece de sentido sin una traducción práctica en una acción

en una postdata, escribía a su amigo el duque de Villahermosa: "La reina mi sobrina ha sido persuadida de sus mayores se convierta, a pena que perderá lo de sus pasados. Responde que primero morirá a cualquier martirio y perderá no sólo lo que tiene, pero cuantos reinos haya en el mundo, que se retire de su opinión. Su hijo está en corte y se le sufre que no oye misa ni se cría so la disciplina católica". Este hijo era el futuro Enrique IV de Francia. Ante un Breve del papa y una carta de Antenori, dirigidos a don Pedro, temía Viterbo que el titular de Comminges no se pudiera contener sin hacer algún gasto, "puesto que no lo ha sabido hacer en esta feria en gastar 150 escudos en tantos arcabuces para llevarlos a su obispado y hacerlos probar todos en su presencia en un prado vecino". Su paso por el concilio fue muy fugaz y apenas dejó huella. El 12 de julio de 1563 tuvo su primera y última intervención. Se discutían los abusos referentes al sacramento del Orden y don Pedro dijo que sobre ellos daría su voto escrito al secretario. Tres días más tarde firmó la sesión XXIII de esta manera: Petrus Alebretus, episcopus Convenarum, hispanus. El cardenal Morone, legado del papa en el concilio, daba a Borromeo, con fecha 12 de septiembre de 1563, esta noticia, la última que poseemos relacionada con la estancia de don Pedro en el Concilio: "Han entendido en Francia por aviso de Mons. Allibret, que ya en Roma fue embajador del rey de Navarra, que en el concilio se trataba de privar a la reina de Navarra y a sus hijos, y esta voz había dado causa de alguna inquietud entre los hugonotes; pero para estas horas se habrá sosegado, habiendo cesado la sospechas". En aquel momento el rey publicó un edicto para la venta de una parte de los bienes temporales del clero, con destino al pago de los gastos de las primeras guerras civiles. Varios obispos reunidos en Trento protestaron contra los proyectos de Carlos IX e intentaron impedir su realización. Pedro Labrit rehusó tomar partido con ellos contra el soberano. El 25 de septiembre de 1563 comunicó a la reina Catalina de Médicis que partía de Trento para no intervenir con ellos contra el rey, considerando la ingratitud de aquellos que habían recibido todos sus bienes de manos de su Majestad. Él estaba dispuesto a entregar al servicio del soberano lo temporal, lo espiritual y hasta su propia vida, si fuera preciso. El 15 de noviembre de [1563] don Pedro de Navarra dirigió una carta a sus hermanos Juan y Diego de Gabiría, en la que les comunicaba: "De Trento y Roma os tengo escrito, que yo volvía a mi casa, como lo he hecho, la cual he hallado poco a mi contento por ciertas cosas, las cuales remediará Dios con el tiempo». El prelado venía gastado y cansado. Su sobrina le pedía una pensión para un deudo. Ellos no debían moverse para ir a verle por muchos inconvenientes. Si los puertos se hallasen transitables, probablemente estaría en Estella el día de Navidad con solos cuatro o cinco de caballo por un negocio de su obispado. Si no viniere, sería por el mal tiempo o porque en Comminges habría en qué entender por el servicio de Dios y conservación de su grey. Pedro estaba malo, como lo era. No había querido quedarse en Italia, sino venir a torreznear. Miguel estaba bueno y cumplía su deber. Diego debía ir a visitar a la mariscala para entregarle la carta que le adjuntaba. El principal objetivo del viaje de don Pedro sería visitarla. "Acabo con rogar a Dios os guarde de mal y pecado. De Sant Beltrán, a 15 de noviembre. Vuestro hermano habrá honra". 
social, o en una operatividad sobre el entorno. ${ }^{48}$ Pero he aquí que Pedro de Navarra se nos muestra con una complejidad que, debo confesar, a veces llega a superar los más acendrados esquemas apriorísticos: ¿cómo concilliar la activa participación en la contrarreforma tridentina, la salvaguarda de los príncipes y reyes a los que sirve y garantizan su estatus, sus intereses personales, cuando tan cercano se veía al sueño de ver en sí mismo la de esperanza la restitución del reino de Navarra, con los pequeños detalles de una cotidianeidad que lo ensamblan a una configuración social rústica y familiar...? Puedo seguir forjando preguntas, cada vez más complejas. Pero todas ellas me llevan a una conclusión: la de un humanista formado en interacción con un medio heterogéneo, desigual, capaz de perseguir hasta la muerte cualquier atisbo de disidencia, como en los autos de fe de Valladolid, ${ }^{49}$ o capaz de sentar en un mismo concilio nacional a las facciones más opuestas, a fin de llegar a un acuerdo mínimo, como ocurrió en el coloquio de Poissy en Francia. ${ }^{50}$ Un entorno que, en todo caso, sólo tendría relevancia en tanto en cuanto no afectara a sus intereses y a su afán de medro personal, que indiscutiblemente, no estaban reñidos con su philosophia vitae, la de alguien que perseguirá la consecución del «desengaño» neoestoico en una vida utópicamente ligada a la naturaleza ${ }^{51}$ de un país, de unas tierras que consideraba como propias por linaje, y ocupadas por una fuerza extranjera, la que representaba Felipe II en definitiva, como heredero de la expansión territorial de las coronas de Castilla y Aragón. Y ante este escollo, verdadero Scila y Caribdis para los que han leído a Pedro de Navarra y tienen noticia de su biografía, ya desde la vertiente hispánica o desde la francesa, las soluciones sólo pueden encontrarse

\footnotetext{
${ }^{48} \mathrm{Vid}$. las observaciones sobre el «yo dividido» de Petrarca y la autoconsciencia del Renacimiento en M. Calinescu, Cinco caras de la modernidad: Modernismo, vanguardia, decadencia, kitsch, posmodernismo, Madrid, Tecnos, 1991, pp. 31-33 y D. Frisby, «Walter Benjamin: La prehistoria de la modernidad», Fragmentos de la modernidad. Teorías de la modernidad en la obra de Simmel, Kracauer y Benjamin, Madrid, Visor, 1992, pp. 336 passim.

${ }^{49} \mathrm{Vid}$. el panorama completo que presentan J. Pérez Villanueva y B. Escandell Bonet, Historia de la Inquisición en España y América, I, El conocimiento científico y el proceso histórico de la Inquisición (14781834), Madrid, Biblioteca de Autores Cristianos - Centro de Estudios Inquisitoriales, 1984; Historia de la Inquisición en España y América, II, Las estructuras del Santo Oficio, Madrid, Centro de Estudios Inquisitoriales - Biblioteca de Autores Cristianos, 1993 y Historia de la Inquisición en España y América, III, Temas y problemas, Madrid, La Editorial Católica - Centro de Estudios Inquisitoriales, 2000.

${ }^{50}$ Vid. A. de Ruble, Le Colloque de Poissy (septembre-octobre 1561), Parías, H. Champion, 1889.

${ }^{51}$ Vid. H. Schulte, El Desengaño. Wort und Thema in der spanischen Literatur des Goldenen Zeitalters, Munich, Wilhelm Fink Verlag, 1969.
} 
en su obra, y no en una lectura literal de ellas, sino en una lectura que tenga muy en cuenta la tipología de intertextualidad que ha definido con certera precisión C. Lara Rallo, en el sentido de que, a partir de las propuestas de A. Jefferson, nos encontremos ante la «necesidad de articular un tipo de relación intertextual que englobe las interacciones existentes en el corpus formado por las obras de un mismo autor», desde las diferencia del hablar al escribir hasta la programación dialogada de un ars moriendi, y más aún, la «conexión existente entre su trayectoria creativa y su autobiografía», ${ }^{52}$ aspectos ambos que van a ser iterativos, constantes y, más aún, ictus determinantes de un iter donde escritura y vida van inextricablemente unidas, y cada «comentario» $\mathrm{o}$ referencia a una determinada etapa vivencial deviene en comentario sobre la codificación expresiva subyacente a la expresión de esa vivencia, en este caso, y de manera preferente, la opción dialógica. ${ }^{53}$

\subsubsection{B. de Montluc.}

Blaise de Montluc se hará eco en sus Commentaires de un suceso que lo relaciona directamente con Pedro de Navarra. En una carta dirigida a Felipe II, fechada en Viella, a 15 de abril de 1564, aborda un tema que no deja de ser espinoso para los historiadores posteriores. Se trata de la conjura entre diversos notables para facilitar que Felipe II pudiera apoderarse de la Guyena francesa, en manos de los «herejes». En ella, supuestamente, participaron Blaise de Montluc, el cardenal de Armagnac y Pedro de Navarra entre otros:

\footnotetext{
${ }^{52}$ C. Lara Rallo, Las voces y los ecos. Perspectivas sobre la intertextualidad, Universidad de Málaga, Málaga, 2006, p. 54 passim. La autora remite a A. Jefferson, «Autobiography as Intertext: Barthes, Sarraute, Robbe-Grillet», en M. Worton y J. Still, eds., Intertextuality. Theories and Practices, Manchester University Press, Manchester, 1990, pp. 108-129.

${ }^{53}$ Remito para un entendimiento de esta interrelación entre vida y opción genérica a las aportaciones recogidas en G. Mazzacurati y E. M. Plaisance, Scritture di scritture. Testi, generi, modelli nel Rinascimento, Roma, Bulzoni, 1987, y en particular al «bilancio del seminario» que lleva a cabo P. Larivaille, «Fra re(-)citazioni e ri(-)creazioni. Noterelle e divagazioni intorno alla riscrittura del Rinascimento» (pp. 691-728). De la imitatio vitae a la imitatio stili transcurriremos un camino arduo y ancho, tanto como el que separa y une monografías como las de E. Kris y O. Kurz, La leyenda del artista, Madrid, Cátedra, 1982; y la de A. Blunt, La teoría de las artes en Italia (de 1450 a 1600), Madrid, Cátedra, 1982. Vid. E. Neumann, Mitos de artista. Estudio psicohistórico sobre la creatvidad, Madrid, Tecnos, 1992. Sobre la «opción dialógica», siguen teniendo plena vigencia las páginas de E. Tierno Galván, Razón mecánica y razón dialéctica, Madrid, Tecnos, 1969, a las que pueden adjuntarse las precisiones de L. Schwartz, «El diálogo en la cultura áurea: de los textos al género», Ínsula, 542 (febrero 1992), pp. 1-2 y 27-28, a las que no dudaría en sumar las que tratan sobre «Poema y diálogo» en H. G. Gadamer, Poema y diálogo, Barcelona, Gedisa, 1993, pp. 142-154.
} 
La personne que ces hérétiques haïssent le plus et qu'ils veulent faire disparaître est V. Majesté, dans la crainte qu'ils ont qu'Elle ne soit leur ruine et leur châtiment; et dans ce but ils font leur possible pour brouiller V. M. avec la Reine-mère et son fils... (?) Ce qui le prouve c'est que, par ordre de ladite princesse, un hérétique nommé Rapin, capitaine de cavalerie, est allé trouver la Reine-mère et son fils, avec un écrit signé par elle et par quatre vicomtes ainsi que par d'autres chevaliers de cette opinion, disant que M. de Monluc, M. Damville, M. de Terride, le vicomte de Lort, M. de Lusa, le cardinal d'Armagnac et Dom Pedro de Labrit se sont assemblés et ont convenu de donner à V. M. toute la Guyenne et qu'ils ont envoyé cette résolution à V. M. par un fils dudit Monluc. Et afin de faire croire cette fausseté à la Reine-mère il s'est présenté à la prison et elle lui a donné la signature (??). Mais le tout a été reconnu faux; on procède maintenant contre les signataires de la pétition. Cette invention a été imaginée par soixante-dix religieux apostats et mariés, formant le conseil de ladite princesse à laquelle V. M. demeure fort obligée pour une si bonne oeuvre! $!^{54}$

En los Commentaires de Blaise de Montluc referidos a marzo de 1563 encontramos el siguiente pasaje:

Quelque temps après, monsieur le cardinal d'Armagnac et la cour de Parlement de Thoulouse et les capitouls m'envoyèrent prier si je voulois aller jusques à Thoulouse pour quelques affaires d'importance qu'ils ne me pouvoient escrire, ce que je fis. Il ne me falloit pas semondre deux fois. Et comme je fuz là, ils tindrent un conseil, où se trouvèrent messieurs les cardinaux d'Armagnac et deStrossi, monsieur le premier president Daffis, les seigneurs de Terride, Negrepelice, Forquevaux, du Faur, advocat general du Roy et les capitouls. Ils me remonstrarent qu'ils vouloient dresser un camp pour aller en Languedoc, et qu'ils me vouloient eslire chef de l'armée. Mais je leur remonstray que monsieur le connestable $\mathrm{n}^{\prime} \mathrm{y}$ prendroit pas plaisir, veu que c'estoit en son gouvernement, et que $\mathrm{d}^{\prime}$ ailleurs il ne $\mathrm{m}^{\prime}$ aimoit guières. ${ }^{55}$

\footnotetext{
${ }^{54}$ Anexo a «Carta de Pedro de Navarra a Felipe II» (Viella, 15 de abril de 1564), Archivo General de Simancas, Estado, K, 1501, n. ${ }^{\circ} 68$.

${ }_{55}$ B. de Montluc, Commentaires: 1521-1576, I, prólogo de Jean Giono, texto establecido y notas P. Courteault, París, Gallimard, 1964, pp. 575-576. La primera edición de estos comentarios se debe a A. de Ruble, Commentaires et lettres, I-V, ed. A. de Ruble, París, Société de l'Histoire de France, 1864-1872; ed. electrónica dividida en cinco unidades numeradas con el título Commentaires et lettres de Blaise de Montluc, maréchal de France, París, Société de l'histoire de France, 2002. Los Commentaires ocupan los vols. I-III (1864-1867) y las Lettres ocupan los vols. IV-V (1870-1872). Para Pedro de Navarra, Iv, p. 331.
} 
P. Courteault, al anotar este pasaje, evidenciaría la relación existente entre la conjura que nos relata Pedro de Navarra y lo que Montluc describe. P. Courteault aduce que aquí hay una «allusion volontairement obscure à la constitution d'une ligue catholique, dont l'acte fut signé le 2 mars à Toulouse par les cardinaux d'Armagnac et Strozzi, Monluc, Terride, Negrepelisse, Fourquevaux et Joyeuse, et que le Parlement approuva le 20. Cet acte fut désapprouvé par la reine; d'où le prudent silence de Monluc». ${ }^{56}$ Lo cierto es que Pedro de Navarra no figura en esta lista, aunque él se «autoimplique» al escribir al Rey dando una lista de conjurados. De hecho algunos historiadores se han hecho eco de su complicidad, como A. Degert, quien afirma que «il fut même soupçonné de lui servir d'agent pour amener Montluc à lui livrer la Guyenne».57

\subsection{Bibliografía repertoriada del siglo xvii}

En Antonio de Herrera (1606-1612) podemos documentar el testimonio de la reacción airada de Felipe II ante el hecho de que Pío IV admitiese a Pedro de Navarra en calidad de embajador de los reyes de Navarra, Antonio de Vendôme y Juana de Albret. ${ }^{58}$

\subsubsection{Fray Antonio de Yepes (1610)}

En la Corónica general de la Orden de San Benito ${ }^{59}$ encontramos la primera anotación relevante impresa sobre Pedro de Navarra, y en ella se acuña una imagen que va a tener una manifiesta proliferación en muchas de las referencias posteriores que iremos analizando. Son unas notas muy breves y concisas, pero de gran fecundidad:

Hombre de ingenio peregrino y raro $^{60}$

\footnotetext{
${ }^{56}$ P. Courteault, anotaciones a B. de Monluc, Commentaires: 1521-1576, II, p. 1249.

${ }^{57}$ A. Degert, «Albret (Pierre d')» (1933), col. 1322.

${ }^{58}$ A. de Herrera, Primera (-tercera) parte de la Historia general del mundo, de XVII años del tiempo del señor rey don Felipe II el Prudente, dese el año de MDLIIII, hasta el de MDLXX, III, Valladolid, J. Godinez de Millis, 1612. La referencia en III, 2.

${ }^{59}$ A. de Yepes, Corónica General de la Orden de San Benito, Patriarca de Religiosos. Por el maestro Fray Antonio de Yepes. Tomo III. Centuria III. Con licencia, y privilegio, En la Universidad de N. ${ }^{a}$ S. ${ }^{a}$ la Real de Yrache, de la Orden de San Benito. Por Nicolás de Assiayn Impressor del Reyno de Navarra. Año 1610. La obra en su totalidad, compuesta de siete tomos, se publicaría entre 1609 y 1621 en Irache, Pamplona y Valladolid. Existe una edición moderna: Crónica general de la Orden de San Benito, II, ed. J. Pérez de Urbel, Madrid, Atlas (Biblioteca de Autores Españoles, 124) 1960.

${ }^{60}$ A. de Yepes, op. cit., f. 378v.
} 
La primera operación selectiva que se suele realizar sobre esta nota caracteriológica es la de reducirla a su primer término. Muchos han sido los que sólo toman de Yepes el «hombre de ingenio», eliminando los rasgos de «peregrino» y «raro», cuya consecuencia más directa será la de abocar a una interpretación totalmente distinta o sin los matices que Yepes adjunta.

Para elucidar lo que debería entenderse por «hombre de ingenio peregrino y raro», en el sentido qure Yepes pudo procurar a su aserción, podríamos acudir como un primer paso a la definición de ingenio tal como la encontramos en Huarte de San Juan:

Y pues el sujeto total de esta obra es el ingenio y habilidad de los hombres, razón será, por lo dicho, que sepamos su difinición y qué es lo que contiene en su esencia; porque, sabida y entendida como conviene, habremos hallado el verdadero medio para hacer demostración de esta nueva doctrina.

Y porque el nombre, como dice Platón, est instrumentum docendi discernendique rerum substantias, es de saber que este nombre, ingenio, desciende de uno de estos tres verbos latinos: gigno, ingigno, ingenero; y de este último parece que tiene más clara su descendencia, atento a las muchas letras y sílabas que de él vemos que toma, y lo que de su significación diremos después.

La razón en que se fundaron los primeros que lo inventaron no debió ser liviana; porque saber imaginar los nombres con la consonancia y buen sonido que piden las cosas nuevamente halladas es obra (dice Platón) de hombres heroicos y de alta consideración. Como pareció en la invención de este nombre, ingenio, que para descibrirla fue menester una contemplación muy delicada y llena de filosofía natural. En la cual discurriendo, hallaron que había en el hombre dos potencias generativas: una común con los brutos animales y plantas, y otra participante con las sustancias espirituales, Dios y los ángeles. De la primera no hay que tratar por ser tan manifiesta y notoria; la segunda es la que tiene alguna dificultad, por no ser sus partos y manera de engendrar al vulgo tan conocidos.

Pero hablando con los filósofos naturales, ellos bien saben que el entendimiento es potencia generativa y que se empreña y pare, y que tiene hijos y nietos, y una partera (dice Platón) que le ayuda a parir. Porque la manera que en la primera generación el animal o planta da ser real y sustantífico a su hijo, no lo tiniendo antes de la generación, así el entendimiento tiene virtud y fuerzas naturales de producir y parir dentro 
de sí un hijo, al cual llaman los filósofos naturales noticia o concepto, que es verbum mentis. ${ }^{61}$

El ingenio va ligado, por tanto, a la fecundidad de la inteligencia, a la capacidad de engendrar conceptos o figuras que representen la naturaleza de las cosas, y debería ser entendido en un primer término, no como una potencia ligada al arte, sino dependiente del temperamento y del talento natural. Así, Fernando de Herrera ya aducía que el ingenio es

aquella fuerça i potencia natural i aprehensión fácil i nativa en nosotros por la cual somos dispuestos a las operaciones peregrinas y a la noticia sutil de las cosas altas. ${ }^{62}$

Y como facultad de generar conceptos mediante dichas «operaciones peregrinas», se hace inevitable traer a colación a Baltasar Gracián cuando refería que

entendimiento sin agudeza ni conceptos, es sol sin luz, sin rayos, y cuantos brillan en las celestes lumbreras son materiales con los del ingenio. ${ }^{63}$

Siguiendo en la órbita en la que nos situaba Huarte de San Juan, aquí habría que definir el «concepto» como aquello que es generado por el ingenio. Tal como Gracián ya apuntara en una observación que ha generado una ingente bibliografía posterior:

De suerte que se puede definir el concepto: Es un acto del entendimiento, que exprime la correspondencia que se halla entre los objectos. ${ }^{64}$

Por tanto, cuando A. de Yepes califica a Pedro de Navarra como un hombre «de ingenio», es muy posible que tuviera en mente esa noción en los términos que aquí he apuntado: como una persona dotada por naturaleza para

\footnotetext{
${ }^{61}$ J. Huarte de San Juan, Examen de ingenios, ed. Guillermo Serés, Madrid, Cátedra, 1989, pp. 185-188.

${ }^{62}$ F. de Herrera, Anotaciones a la poesía de Garcilaso [581] [v. 948], ed. I. Pepe Sarno y J. M. Reyes Cano, Madrid, Cátedra, 2001, p. 860.

${ }^{63}$ B. Gracián, Agudeza y arte de ingenio, I, ed. E. Correa Calderón, Madrid, Castalia, 1969, p. 50.

${ }^{64}$ Ibidem, p. 55. Vid. las páginas clarificadoras de Ch. V. Aubrun, «El “ingenio" en Huarte de San Juan y otros escritores españoles», en Actas del VI Seminario de Historia de la Filosofía Española, Salamanca, Universidad deSalamanca, 1990, pp. 211-223; y, del mismo, «Baltasar Gracián y el Ingenio», Cuadernos Salmantinos de Filosofía, xvI (1989), pp. 177-189.
} 
engendrar conceptos en un acto del entendimiento, es decir, exprimiendo la correspondencia que pueda hallarse entre los objetos a los que dedica su labor intelectual. Precisamente en su capacidad de hacer corresponder esos objetos o de hallar correspondencias entre esos objetos para dar «noticia sutil de las cosas altas» es donde cobraría sentido el calificativo «peregrino» que le aplica A. de Yepes.

En Covarrubias, la última acepción de «peregrina» se hace equivaler a «cosa rara», ${ }^{65}$ y en el Diccionario de Autoridades, la tercera acepción de «peregrino» vuelve a ser acogida:

Por extensión se toma algunas veces por extraño, raro, especial en su línea, o pocas veces visto. Lat. Peregrinus, a, um. Insolens. Rarus. ${ }^{66}$

Está claro que, avanzando un paso más, «en esta capacidad del escritor para crear relaciones y establecer correspondencias, para engendrar conceptos, consiste la verdadera agudeza codificada por Gracián». ${ }^{67}$ Es esta capacidad la que es calificada de peregrina y rara de forma redundante, teniendo en cuenta que hay procedimientos cronológica e ideológicamente más simples o más complejos de hallar estas correspondencias, y a Pedro de Navarra se le alaba por ser un hombre de ingenio capaz de establecer tipos extraños, raros, especiales en su singularidad o pocas veces vistos en su modo de conformar los conceptos. Así es como debía verlo A. de Yepes cuando escribía sobre Pedro de Navarra a principios del siglo XVII, y así lo deja entrever el propio humanista en sus Diálogos de la diferencia del hablar al escrebir, de los que podría desprenderse la idea de que

decifrare nel testo il significato del nome cogliendone il livello referenziale, e così avere l'idea dell'ente perfettissimo vuol dire non solo cogliere il

\footnotetext{
${ }^{65}$ S. de Covarrubias, Tesoro de la lengua castellana o española según la impresión de 1611, con las adiciones de Benito Remigio Noydens publicadas en la de 1674, ed. M. de Riquer, Barcelona, Alta Fulla, $1989^{2}$.

${ }^{66}$ Diccionario de Autoridades de la Real Academia Española I-III (ed. facsímil de la de 1726-1734), Madrid, Gredos, 1984. Sobre las acepciones de "peregrino», analizadas en el contexto de un entramado textual concreto desde su polivalencia, vid. G. Cabello Porras, «El motivo de la peregrinatio en Soto de Rojas: sumarización ejemplar de un itinerario en la vida y en la literatura», Analecta Malacitana, x, 1 (1987), pp. 81-106, y x, 2 (1987), pp. 273-318; y Barroco y Cancionero. El «Desengaño de amor en rimas» de Pedro Soto de Rojas, Universidad de Almería-Universidad de Málaga, Málaga, 2004, pp. 417-509.

${ }^{67}$ F. Lázaro Carreter, «Sobre la dificultad conceptista», Estilo barroco y personalidad creadora, Madrid, Cátedra, $1977^{3}$, p. 16.
} 
livello referenziale, ma anche i possibili livelli di riferimenti dell'intera catena gerarchica. Ma per raggiungere il senso di questo risultato è preliminarmente necessario analizzare innanzitutto la difformità tra definizione e uso dei vocaboli. ${ }^{68}$

\subsubsection{A. Galland (1613)}

La visión que nos ofrece de Pedro de Navarra A. Galland va a ser no menos decisiva para los tratamientos posteriores de su figura. ${ }^{69}$ Nos muestra, en primer lugar, a un Pedro de Navarra como embajador de los intereses del reino de Navarra ante Felipe II, y seguidamente, ante el recién nombrado papa Pío IV. Retrata a un hábil negociador, con los objetivos muy claros y poco dispuesto a ceder ante las presiones hostiles del bando contrario.

De la semblanza que realiza interesa resaltar aquí una serie de cualidades que, más que en el propio texto de Galland, las encontramos en los testimonios epistolares que el autor recoge para documentar sus asertos. En dichas cartas se

\footnotetext{
${ }^{68}$ R. Diodato, Vermeer, Góngora, Spinoza. L'estetica come scienza intuitiva, Milán, Bruno Mondadori, 1997, p. 32, donde apunta a cuestiones que ya se había planteado Pedro de Navarra en los citados diálogos, en el sentido de que «il significato delle varie parti dil discorso dipende dal livello di riferimento gnoseologico e ontologico nel quale sono inserite: nomi, parole, etichette verbali in genere, e sopratutto avverbi, deittici, preposizioni possono indicare, senza mutare significante, cose dell'intelletto o cose dell'immaginazione e gli stessi termini possono funzionare senza denotare realmente alcunché a un livello e a un altro funzionare come schemi dell'ontologia», preocupacón patente en los diálogos en los que se plantea la diferencia entre el simple cronista cortesano o el verdadero historiador desde el plano de acercamiento a los hechos y desde el nivel en el que se sitúan para crear una «narración», la distinción «ontologica», social y lingüística entre un Noble y un Rústico, y los planos expresivos en los que un secretario de estado, trasunto de Francisco de Eraso, debe dialogar con la Muerte. Son muy útiles las páginas que R. Diodato dedica al «numero, ordine, parte / tutto, uno e molti, unità e pluralità» (pp. 33-56), bajo el epígrafe «I nomi, le cose».

${ }^{69}$ A. Galland, Mémoires pour l'histoire de la Navarre et de Flandre, contenants le droit du roy au royaume de Navarre, et aux Duchez de Pegnafiel, de Gandie E de Montblanc, à la Comté de Ribagorce, à la Vicomté de Castelbon, à la Ville de Balaguier, E à la Seigneurie de Castillon de Farfagna, en Castille, Arragon $\mathcal{E}$ Catalogne, vsurpées \& detenuës par les Roys d'Espagne, auec le Royaume de Nauarre, depuis l'an 1512. Le droit partucvlier dv roy comme segnevr des Villes $\mathcal{E}$ Chastellenies de Dunkerque, de Bourbourg, E de Grauelines en Flandres; et comme Seignevr Chastellain de Lille. Auec l'Histoire de cent cinquante années de Guerres d'entre la France \& la Flandre, depuis l'an 1180. jusques en 1331. qui iustifient le droit de la Covronne de France sor les villes \& Chastellenies de Lille, Doüay \& Orchies: et sur la Comté de Flandre et le Pays de Waes. Avec les prevous avtentiques. Le tout dressé sur les Titres \& Memoires du Cabinet de Feu Messire Avgruste Galland, Conseiller du Roy en ses Conseils d'Estat \& Priué, \& Procureur general de sa Maison, Couronne E ancien Domaine de Nauarre. A Paris, Chez Mathiev Gvillemot, ruë sainct Iacques à l'Enseigne de la Bibliotheque. M.DC.X:VIII. Avec privilege dv Roy.
} 
nos relata cómo cuando Pedro de Navarra demandaba a Felipe II la restitución del reino de Navarra a sus legítimos soberanos, ante la negativa del monarca español a tratar siquiera sobre ello, él «insista fort pour la restitution, \& demanda response certaine», sin amilanarse ante la real presencia. ${ }^{70}$

Una vez que cesa por voluntad de Felipe II su misión en España, y es enviado a Roma para intentar conseguir del papa Pío IV que aceptase la obediencia de los reyes de Navarra, lo que implicaba en cierto modo un reconocimiento de su soberanía, son muchos los testimonios que dan cuenta de la admirable negociación que Pedro de Albret llevó a cabo, logrando su objetivo en los términos en que lo había dispuesto: el reconocimiento solemne de la legitimidad de los sobreranos del reino de Navarra.

Las cartas pertenecientes a este periodo nos lo muestran como un hombre que se prepara concienzudamente para las intervenciones que deberá realizar en las audiencias ante el papa: «En quoy ledit Dom Pedro se confiant, est apres à faire provision de harangue \& se preparer pour le Consistoire public permis par sa Sainteté». ${ }^{71}$

Cuando el Papa acepta que se realice el consistorio para que Pedro de Navarra pueda defender públicamente su petición, los testigos hablan de un legado que se expresa brillantemente en español y que se gana la voluntad del pontífice, aun contando con la abierta oposición de los ministros enviados por Felipe II:

\footnotetext{
${ }^{70}$ A. Galland, op. cit., pp. 81-82, nos explica cómo, tras llegar Felipe II a España de su viaje desde los Países Bajos, todos las naciones enviaron embajadores a la corte española. El rey de Navarra envió a Pedro de Albret como tal y le encargó que en su primera audiencia reclamara la restitución de Navarra. A. Galland nos cuenta cómo en un principio Felipe II no quiso escuchar en audiencia al Embajador, para luego concederla a cambio de que no se plantease en ella la restitución de Navarra. Es entonces cuando se deja entrever que, dada la imposibilidad de tratar sobre la restitución del reino de Navarra, Antonio de Vendôme podría optar a alguna «honneste recompense». Las diferentes fases de esta negociación pueden ser seguidas a través de una serie de epístolas del embajador de Francia en España, Sebastien de l'Aubespine, obispo de Limoges, al rey de Francia Francisco II. A. Galland recoge estas epístolas del embajador francés. La primera data del 3 de octubre de 1559 y en ella se nos relata el primer encuentro entre Pedro de Navarra y el rey Felipe II con los resultados ya expuestos. Una vez que se plantea la posibilidad de recompensar con el reino de Cerdeña, la condición que impone Antonio de Vendôme es la de ejercer una soberanía absoluta sobre el territorio, a lo que Felipe II responderá que habrá que esperar a consultar con los Estados de Toledo, que se celebrarían ese mismo invierno. En una segunda carta del 11 de noviembre de 1559, el obispo de Limoges da cuentas al rey de Francia de lo que él mismo había negociado sobre el reino de Navarra.

${ }^{71}$ «Lettre de l'Ambassadeur à Rome sur le sujet de l'obedience du Roy de Navarre. 1560. 25 Novembre» apud A. Galland, op.cit., p. 89.
} 
s'estendit ledit Dom Pedro sur ce propos en langue Espagnole de telle grace \& façon que nostre sainct Pere y print plaisir \& s'en contenta, ainsi que luy-mesme depuis m'a tesmoigné: \& semblablement qu'il estoit resolu de le recevoir comme dessus, nonobstant l'opposition \& l'instance que luy faisoient au contraire les Ministres du Roy Catholique, \& croy fermement que sans deux Festes qui furent la semaine passée. ${ }^{72}$

De esta forma Pedro de Navarra logra que Pío IV acceda a que se celebre el acto en el que los reyes de Navarra le jurarán obediencia en la sala regia, con lo que las presiones de los ministros españoles se intensificarán para intentar deslucir la ceremonia y convertirla en una ceremonia privada. Una vez más, Pedro de Navarra no se arredra ante las dificultades y buscará hasta el final que se cumpla lo prometido originalmente por el pontífice:

desiroit bien que ledit Dom Pedro se contentast de quelque privée reception: ce que ie ne pense pas qu'il consente iamais, ayant tousiours protesté de s'en aller sans rien faire, s'il y manque rien de la ceremonie deuë aux Roys. ${ }^{73}$

En otro testimonio posterior se insiste en esta pertinaz voluntad:

A toutes ces remonstrances \& plusieurs autres qui me furent repliquées par plusieurs fois, ie respondis tousiours à nostre sainct Pere que i'estois asseuré que l'Ambassadeur desdits Roy \& Royne de Navarre ne se contenteroit iamais de ce party. ${ }^{74}$

La ceremonia se llevó a cabo en el lugar y en la fecha que el Papa había otorgado originalmente a Pedro de Navarra, y todos los testimonios documentan que su lectura del discurso preparado por el humanista Marco Antonio Mureto ${ }^{75}$ consiguió para la causa de los reyes de Navarra lo que hasta entonces había sido imposible.

Si el buen «ingenio raro y peregrino» que le atribuía A. de Yepes a Pedro de Albret nos conduce inevitablemente a la condición de un escritor que cumple sabiamente las funciones del rhetoricus, aquí, con el espacio que diseña A. Galland, nos acercamos a una condición complementaria, la de

\footnotetext{
72 «Lettre de l'Evesque du Mans. 1560. 5 Decembre», apud A. Galland, op.cit., p. 90.

${ }^{73}$ Ibidem.

${ }^{74}$ «Lettre de l'Evesque du Mans. 1560. 9 Ianvier avant Pasques», apud A. Galland, op.cit., p. 91.

${ }^{75}$ Vid. supra el apartado 4.1., donde se trata de Muret, y la nota 27, relativa al discurso.
} 
Pedro de Navarra como orator. Ambas son consustanciales a un modelo que algunos estudiosos han insistido en conferir a Pedro de Navarra: el de un humanista del Renacimiento.

Esta atribución al autor de un rasgo como el de humanista debe ser precisada previamente, teniendo en cuenta tanto los argumentos que podrían barajarse a favor o en su contra. Si estrictamente, desde la perspectiva de A. Galland, nos centramos en la actividad política que llevó a cabo Pedro de Labrit, quizá nos encontraríamos aún ante un ejercicio político de tipo medievalizante, escolástico en cierto modo, si tenemos en cuenta los presupuestos desde los que parte N. Rubinstein ${ }^{76}$ cuando contrasta el tipo de actividad política al que se amoldaría la que lleva a cabo Pedro de Navarra con la nueva manera política humanista desde la que se privilegian, fundamentalmente, los intereses de los ciudadanos en un orden parecido al que nos da como ejemplo F. Rico, a partir de textos de Leonardo Bruni o Coluccio Salutati, sobre la igualdad de los estamentos. Leonardo Bruni señalaba que a orillas del Arno

de varios estamentos ha nacido una suerte de igualdad, pues a los mayores los defiende su poder; a los menudos, la república, y a unos y a otros, el temor del castigo... Pareja es la condición de todos, porque la república sale por los fueros de quienes menos pueden. ${ }^{77}$

Y es que para Pedro de Navarra la ciudad, como unidad política, no constituía el centro de su atención. Sus preocupaciones versaban sobre un supuesto imperativo que le conducía a definir y deslindar los deberes y las funciones de los príncipes, los límites de su autoridad y, sobre todo, sus relaciones con la Iglesia en general y con el papado en particular, tal y como hemos visto anteriormente en sus negociaciones con Felipe II y con Pío IV.78

\footnotetext{
${ }^{76}$ N. Rubinstein, «Le dottrine politiche nel rinascimento», en M. Boas Hall, A. Chastel, C. Grayson, D. Hay, P. O. Kristeller, N. Rubinstein, Ch. B. Schmitt, Ch. Trinkaus, W. Ullmann, Il Rinascimento. Interpretazioni e problemi, Roma, Laterza, 1983, pp. 181-237.

${ }_{77}$ Apud F. Rico, El sueño del humanismo (De Petrarca a Erasmo), Madrid, Alianza, 1993, p. 51. Vid. los textos que recoge sobre «La vida política» E. Garin, El Renacimiento italiano, Barcelona, Ariel, 1986, pp. 159-190.

${ }^{78}$ N. Rubinstein, loc. cit., p. 184: «le città, come singole unità politiche, non erano contemplate nelle teorie politiche degli scolastici, la cui preoccupazione era quella di definire i doveri e le funzioni dei prìncipi, i limiti della loro autorità e, soprattutto, il loro rapporto con la Chiesa in generale e il papato in particolare». Vid., sobre el desarrollo de estos presupuestos, las páginas dedicadas al «Escolasticismo y libertad» en los orígenes del Renacimiento, y el apartado que versa sobre «La recepción del pensamiento político humanista» en Q. Skinner, Los fundamentos del pensamiento político moderno. El Renacimiento, México, Fondo de Cultura Económica, 1993, pp. 70-88 y 239-271.
} 
Desde este punto de vista, no estaríamos ante un humanista en sentido estricto. Pero si pensamos en lo que F. Rico denomina el carácter maleable del humanismo cuando se aplica a terrenos tan espinosos como la política y el ejercicio de las cancillerías, deberíamos replantearnos un juicio quizá apresurado. En este sentido, el humanismo proporcionaba a los humanistas

unas vastísimas coordenadas para situar las más diversas experiencias y, en última instancia, les imponía escasas constricciones que no fueran formales, de «estilo», en un orden de cosas en que no pudieran moverse ágilmente, a poco que les apeteciera. En verdad, nunca faltaba un oportuno precedente antiguo para aprobar o rechazar, a conveniencia, tal o cual proceder, tratárase de jugar a la pelota [...], o de zanjar una cuestión de más peso. Esa ductilidad tuvo que ejercer un intenso atractivo sobre la clase dirigente. ${ }^{79}$

Aquí se hace necesario precisar, ya de entrada, en qué sentido voy a emplear el término humanista y si éste podría ser aplicable a Pedro de Navarra. Para ello he recurrido a un texto luminoso de M. Baxandall:

«Humanista» es una palabra que los primeros humanistas no conocieron, tampoco «humanismo». Parece ser que el término humanista tuvo sus orígenes en la jerga universitaria de finales del siglo $\mathrm{XV}$, en la que se empleaba para designar al profesor especialista en studia hunamitatis. La locución studia huanitatis se refería a un programa que los primeros humanistas desarrollaron a partir de ciertos comentarios de Cicerón, un plan de estudios específicos: gramática, retórica, poesía, historia y ética, estudiadas a partir de los mejores autores clásicos. «Humanismo» surgió como una abstracción de todo esto en el siglo XIX, y rápidamente adquirió diversas connotaciones humanitarias e incluso agnósticas. Muy pocas pesan directamente sobre los primeros humanistas. En este libro el término «humanista» se referirá a aquellos que durante los siglos XIV, XV y XVI leían y escribían en latín clásico - y a veces en griego - sobre temas de literatura, historia y ética; el término «humanismo» se refiere simplemente a este tipo de actividades. ${ }^{80}$

\footnotetext{
${ }^{79}$ F. Rico, op. cit., p. 50. Vid. ahora el panorama sumamente clarificador que presenta A. Rallo Gruss, Humanismo y Renacimiento en la literatura española, Madrid, Síntesis, 2007, cuya virtud más notoriamente novedosa, y no la menor, es la atención permanente a la fuentes directas textuales de los humanistas españoles en su imbricación con las fuentes italianas. Para este punto remito al apartado «La dignidad del hombre y el compromiso social», pp. 54-60.

${ }^{80} \mathrm{M}$. Baxandall, Giotto y los oradores. La visión de la pintura en los humanistas italianos y el descubrimiento de la composición pictórica 1350-1450, Madrid, Visor, 1996, pp. 17-18. Para el ámbito de lo que podría
} 
Si con el término «humanista» nos referimos a aquellos que, como aduce M. Baxandall, entre los siglos XIV al XVI, leían y escribían en latín clásico sobre temas de literatura, historia y ética, claramente Pedro de Navarra, si atendemos al amplio espectro de temas que abordó en los diálogos que escribió, tanto los que conservamos, como los que, aunque perdidos, conocemos la materia de la que tratan, podría figurar cabalmente en la nómina de los humanistas. Pero se necesita alguna precisión más, y ésta la proporciona el mismo M. Baxandall:

Cuando los primeros humanistas necesitaban un término que los definiera - por ejemplo, como sección dentro de una colección clasificada de biografías - la palabra que por lo general utilizaban era orator; también, aunque sólo de vez en cuando, rethoricus. Esta última se adaptaba bien al caso, ya que las principales actividades y preocupaciones que los primeros humanistas compartieron fueron - en el sentido más ampliode tipo retórico. ${ }^{81}$

denominarse como «humanismo español» siguen siendo más que pertinentes los intentos de delimitación que encontramos en las páginas de O. di Camillo, El humanismo castellano del siglo XV, Valencia, Fernando Torres, 1976; L. Gil Fernández, Panorama social del humanismo español (1500-1800), Madrid, Tecnos, 19972; y sigue siendo de consulta obligada la colectánea de estudios que figuran en A. Redondo, ed., L'Humanisme dans les lettres espagnoles (XIX ${ }^{e}$ Colloque international d'Études humanistes, Tours 5-17 juillet 1976), París, J. Vrin, 1979, a la que habría que añadir la de AA. VV., Actas del Coloquio Interdisciplinar «Doce consideraciones sobre el mundo hispano-italiano en tiempos de Alfonso y Juan de Valdés» (Bolonia, abril de 1976), Roma, Instituto Español de Lengua y Literatura de Roma, 1979, y la de V. García de la Concha, ed., Academia Literaria Renacentista. V. Literatura en la época del Emperador, Salamanca, Universidad de Salamanca, 1988, y del mismo, La cultura del Renacimiento (1480-1580), Madrid, EspasaCalpe [Historia de españa Menéndez Pidal, 21], 1999. Vid., recientemente, la recuperación de un texto clásico, en versión española de R. Malpartida Tirado: el de A.G. Bell, «Notes on the Spanish Renaissance», Revue Hispanique, LXXX (1930), pp. 319-652; trad. esp. El Renacimiento, Málaga, Universidad de Málaga, 2004. La monografía de D. Ynduráin, Humanismo y Renacimiento en España, Madrid, Cátedra, 2004, presenta un panorama en el que la profusión de datos y la propia estructuración de la obra, induce a cierta confusión, lo que muy posiblemente obedece a causas ajenas al propio autor.

${ }^{81}$ M. Baxandall, op. cit., p. 18. Para la retórica y el humanismo, desde las perspectivas de la relación entre el renacimiento con la retórica clásica y los orígenes mismos de la cultura humanística; de la "crescente tendenza a utilizzare gli strumenti retorici e, in primo luogo, quelli offerti dalle teoria della "dispositio" e dalla "topica", come modulli per la ricostruzione di un ordine generale e sistematico del sapere»; y de los desarrollos de la retórica humanista que «conduscono alla nascita di una concezione critica del linguaggio e alla formazione di una coscienza filologica stessa all'indagine delle più diverse forme di esperienza e di espresssione culturale», es más que clarificador el ensayo de C. Vasoli, «La retorica e la cultura del Rinascimento», Rhetorica, 2, 2 (Summer 1984), pp. 121-137 (la cita en p. 122). Vid., en J. Kraye, ed., Introducción al humanismo renacentista, ed. española a cargo de C. Clavería, Cambridge, Cambridge University Press, 1998, los estudios de M. D. Reeve, «La erudición clásica» (pp. 1-72); K. Jensen, «La reforma humanística de la lengua latina y de su enseñanza» (pp. 93 114); P. Mack, «La retórica y la dialéctica humanísticas» (pp. 115-136); A. Hamilton, «Los humanistas y la Biblia» (pp. 137-157) y J. Kraye, «Filólogos y filósofos» (pp. 189-209). 
Esta observación confirmaría aún más la condición de Pedro de Navarra como humanista, ya que tanto como orator como rheroricus se nos ha mostrado en estos dos primeros acercamientos a su figura, los de Yepes y los de Galland, a los que se suman los testimonios que éste último aporta de los personajes coetáneos que dieron testimonio de los modos y maneras del escritor, sin dejar de lado la posición relevante que ocuparían en este sentido los Diálogos de la diferencia del hablar al escrebir.

Sigo con M. Baxandall cuando escribe:

Dentro de la gama de los studia humanitatis los intereses de cada humanista eran, como es natural, distintos; muchos de ellos escribieron sobre ética, otros se dedicaron principalmente a los temas históricos; casi todos ellos escribieron cartas y pequeñas composiciones epistolares sobre la vida; algunos - relativamente pocos - escribieron versos, y así sucesivamente. $^{.2}$

Denuevo aquí Pedro de Navarra cumpliría estos «requisitos» del modelo de humanista que traza Baxandall, como un intelectual capaz de abordar las materias más diversas ${ }^{83}$ y en una gama amplia de opciones genéricas. ${ }^{84}$

\footnotetext{
${ }^{82}$ M. Baxandall, op. cit., p. 18. Para la adecuación y las relaciones entre la retórica y los géneros literarios sigue siendo imprescindible el marco operativo que diseña G. B. Conte, Genre and Poetic Memory in Virgil and Other Latin Poets, traducción del italiano de Ch. Segal, Ithaca - Londres, Cornell University Press, 1986, especialmente en el apartado «Poetic Memory: Its Historical and Systematic Features», pp. 52-68, donde da cuenta de las «Allusion and Rhetorical Figures».

${ }^{83}$ Para el caso concreto de Pedro de Navarra habría que tener en cuenta las consideraciones que realiza sobre la retórica aristotélica, y el Renacimiento y el «Second Scholasticism», W. A. Wallace, "Aristotelian Science and Rhetoric in Transition: The Middle Ages and the Renaissance», Rhetorica, 7 (Winter 1989), pp. 7-21.

${ }^{84} \mathrm{Vid}$. las consideraciones de L. E. Rossi, «I generi letterari e le loro leggi scritte e non scritte nelle letterature classiche», Bulletin of the Institute of Classical Studies, 18 (1971), pp. 69-94, donde apunta, lo que es válido para las opciones genéricas de Pedro de Navarra y su relación intertextual con sus fuentes, que «le scelte espressive (e penso alla lingua stessa) sono tutte in una certa missura «obbligate», condizionate cioè da una tradizione che le carica di certi contenuti o valenze espressive, indipendentemente dalla fissazione scritta di leggi. Tali leggi da una parte non possono essere ignorate anche quando stano non scritte, e dall'altra, anche se codificate, possono essere ignorate in virtù di una scelta innovatrice, che svecchi dei moduli espressivi e li rivolga con intenzione ad altre più o meno imprevedute direzioni» (pp. 72-73). En este caso nos encontraríamos, desde la óptica de las opciones genéricas, en la órbita de la intertextualidad desde «perspectivas político-ideológicas y silenciadas», fenómeno que ha sido analizado de forma concluyente por C. Lara Rallo, Las voces y los ecos. Perspectivas sobre la intertextualidad, Málaga, Universidad de Málaga, 2007, pp. 113-136.
} 
Sus diálogos sobre las diferencias entre la vida rústica y la noble o los que dedica a la preparación de la muerte, por poner un ejemplo, lo sitúan de lleno en el terreno de la ética, adentrándose, en estos últimos, en los linderos de un ars moriendi de evidente prefiguración del desengaño contrarreformista barroco; ${ }^{85}$ los que escribió acerca de cómo deberían ser los cronistas de los príncipes, en el ámbito de la historia; su epistolario, sobre todo el que escribe al final de su vida, se asemeja al que Petrarca nos dejó también al final de la suya, como describe F. Rico, cuando señala que «el humanista se consagra a componer unos textos más ágiles, menos exigentes, que salgan al encuentro de la vida diaria, los avatares de la política, las relaciones de amistad, los problemas éticos, las grandes cuestiones intelectuales, para probar que el legado antiguo es la cultura humana que mejor acompaña las enseñanzas de la religión». ${ }^{86}$

Añade M. Baxandall un rasgo más:

Lo que todos ellos tuvieron en común fue el medio tan estricto y singular del latín neoclásico, y neoclásico no sólo en cuanto a gramática sino también en cuanto a la totalidad de estilo y carácter. A causa de las dificultades que presentaba tuvieron que dedicarle un gran esfuerzo $\mathrm{y}$, según ellos mismos, la destreza en este campo era la medida específica que determinaba la talla de cada individuo. ${ }^{87}$

De esto queda amplia constancia tanto en su labor como embajador o como eclesiástico que asistió a las últimas convocatorias del concilio de Trento,

\footnotetext{
${ }^{85}$ No deja de sorprender que F. Martínez Gil, Muerte y sociedad en la España de los Austrias, Madrid, Siglo XXI, 1993, haya pasado por alto estos diálogos en su monografía.

${ }^{86}$ F. Rico, op. cit., p. 60. Vid., sobre le «raccolte epistolari» las páginas de R. Amaturo, Petrarca, Bari, Laterza, 1988³ , pp. 167-220. También K. Foster, Petrarca. Poeta y humanista, Barcelona, Crítica, 1989, pp. 205-212 y las páginas sobre «la prosa e la tematica religiosa e morale» debidas a A. Noferi, L'esperienza poetica del Petrarca, Florencia, Felice Le Monnier, 1962, pp. 20-35.

${ }^{87}$ M. Baxandall, op. cit., p. 18. No obstante, para el caso de Pedro de Navarra su «destreza» en este campo debe medirse con el rasero de los géneros retóricos medievales (ars poetriae, ars dictamini y ars praedicandi), tal como los analiza J. J. Murphy, La retórica en la Edad Media. Historia de la teoría de la retórica desde San Agustín hasta el Renacimiento, México, Fondo de Cultura Económica, 1986, pp. 145-361, más que desde una perspectiva estrictamente humanística. Vid. M. Fumaroli, L'âge de l'éloquence. Rétorique et «res litteraria»" de la Renaissance au seuil de l'époque classique, Ginebra, Droz, 1980.
} 
como a través del bagaje cultural clásico, en su vertiente clásica grecolatina y en la bíblica y patrística, que sus obras dejan traslucir de forma evidente.

Revisados estos rasgos que deberían conformar el paradigma de «humanista», si hubiera que determinar la «talla como individuo» de Pedro de Navarra desde esa perspectiva, pocas dudas cabría plantearse sobre su acomodación ejemplar al modelo aquí esbozado, siguiendo a M. Baxandall, quien, en su conclusión, nos reconduce al terreno en el que habíamos iniciado esta exposición a partir de A. Galland, el de la retórica y la gramática, a las que debe unirse la oratoria, cuando asevera que muchos humanistas

se sirvieron de esta destreza para hacer carrera como secretarios de la Curia de Roma o de la Cancillería de Florencia, como maestros en Mantua, Ferrara o Nápoles. El arte de los humanistas radicaba en la gramática y la retórica latinas. ${ }^{88}$

\subsubsection{G. de Catel (1633)}

El nombre de Pierre d'Albret figura en el catálogo de los obispos de Cominges, sin ningún tipo de anotación, entre su predecesor, Carlos Carafa, y su sucesor, Carlos de Borbón, sin proporcionar ningún dato adicional, ni siquiera el de las fechas en las que ejerció su cargo. ${ }^{89} \mathrm{Su}$ inclusión aquí viene justifacada por el uso posterior que se hará de esta referencia bibliográfica, no siempre ajustado a lo que estrictamente puede leerse en ella. Será el Conde de la Viñaza quien primero recurra a ella: ${ }^{90}$

\footnotetext{
${ }^{88}$ M. Baxandall, op. cit., p. 18. Vid. S. Bertelli, «Il concetto di corte», en D. Bigalli, ed., Ragione e «civilitas». Figure del vivere associato nella cultura del '500 europeo, Milán, Angeli, 1986, pp. 141-146, y las ponencias incluidas en el volumen La corte e il «cortegiano», Roma, Bulzoni, 1980. El tomo I: C. Ossola, ed., La scena del testo. El tomo II: A. Prosperi, ed., Un modello europeo. Siguen teniendo vigencia el estudio de M. Morreale, Castiglione y Boscán: el ideal cortesano en el Renacimiento, Madrid, Anejos del Boletín de la real Academia Española I, 1959 y la obra ya citada de L. Terracini, Lingue come problema..., desde esta perspectiva en la que conjugan lengua clásica / lengua moderna / res publica.

${ }^{89} \mathrm{G}$. de Catel, Mémoires de l'histoire du Languedoc, curieusement et fidèlement recueillis de divers auteurs... et de plusieurs titres et chartes..., Tolosa, P. Bosc, 1633.

${ }^{90}$ Conde de la Viñaza, Bibliografía histórica de la filología castellana, Madrid, Imprenta y fundición de Manuel Tello, 1893, año 1590, pp. 455-457, cols. 906-910. Existe reedición facsímil en Madrid, Atlas, 1978, en dos tomos.
} 
Gregorio Cabello Porras

Charles Carrafa. Neapolitain fut creé Cardinal par le Pape Paul 4. \& fait euesque de Comenge à la nomination du Roy Henry $2^{91}$

Pierre d'Albret.

Charles de Bovrbon frere naturel du Roy Henry IV. apres auoir esté Euesque de Comenge fut transferé à l'Euesché de Lectoure \& puis à 1'Archuesché de Roüen. ${ }^{92}$

${ }^{91}$ El personaje del cardenal Carlos Carafa, nepote del papa Paulo IV, y predecesor de Pedro de Navarra en el obispado de Cominges, Su figura va a adquirir un lugar relevante en algunos pasajes de su obra, incluidas las alusiones que le dedica en los Diálogos de las herejías de Francia. Sobre este personaje se hace imprescindible el estudio de G. Duruy, Le cardinal Carlo Carafa (15191561). Étude sur le pontificat de Paul IV, París, Hachette et C $C^{\mathrm{ie}}, 1882$. Cabe recordar aquí cómo fue el mismo Paulo IV el que, tras elevar a Carlos Carafa y a otros de sus nepotes a las máximas instancias de poder en la política internacional, vio claramente «los inicuos y criminales pasos de sus sobrinos». Como leemos en R. García-Villoslada, «Felipe II y la Contrarreforma católica», en R. García-Villoslada, ed., Historia de la Iglesia en España, III, 2. ${ }^{\circ}$, La Iglesia en la España de los siglos XV y XVI, en J. L. González Novalín, Historia de la Iglesia en España. III-2. ${ }^{\circ}$ La Iglesia en la España de los siglos XV y XVI, en R. García-Villoslada, ed., Historia de la Iglesia en España, Madrid, Biblioteca de Autores Cristianos, 1980, pp. 47-48: «Su desengaño fue terrible, y empezó a hacer justicia, empezando por sus más maquiavélicos nepotes; el cardenal secretario de Estado, Carlos Carafa, y el capitán general de la Iglesia y comandante de las galeras pontificias: Giovanni Carafa. Ambos fueron mandados al exilio y despojados de todos sus títulos, honores y cargos (salvo el título cardenalicio de Carlos). El castigo más riguroso los recibirán bajo el pontífice siguiente. [...] Se le ha reprochado a Felipe II el no haber intervenido con su gran autoridad en favor de los Carafas, que se habían reconciliado en los últimos años con él. Por lo menos permitió que su embajador Vargas los defendiera en lo posible. Él se contentó con dejar que los jueces hicieran justicia.[...] Carlos, el más intrigante, maquiavélico y aventurero, autor de la guerra antiespañola, despertado en su cama del castillo de Sant' Angelo en la noche del 5 de marzo de 1561, fue estrangulado con horrible tortura, que duró casi una hora por haberse roto la cuerda. Poco después fue decapitado Juan Carafa, duque de Paliano, adúltero y uxoricida, con otros personajes de cuenta». Sobre él puede leerse en J. Contrasty, Histoire des évêques de Comminges, Toulouse, Sistac, 1940, p. 294, una semblanza tomada de Henri Lemonnier:: «Il faut voir en ce cardinal, dit un historien, un des derniers condottières italiens, héritiers de l'audace, des talents et des vices des condottières du $\mathrm{XV}^{\mathrm{e}}$ siècle. Ambitieux, agité, terrible dans ses haines, sans aucun scrupule; il avait commis au moins deux assassinats. Il devint néanmoins tout puissant auprès de son oncle, qui tout d'abord avait été tenté de le renier». El propio J. Contrasty concluye sobre este personaje: «Pour notre part, prenons cet étrange personnage pour un simple fermier des fruits décimaux du Comminges. Il était venu en France pour promouvoir la guerre contre les Espagnols, et le roi lui paya la commission avec une monnaie qui ne lui appartenait pas».

${ }^{92}$ G. de Catel, op. cit., fol. 1038. 


\subsubsection{A. d'Oihénart (1637)}

Arnaud d'Oihenart, hombre de leyes y humanista navarro, recoge la siguiente noticia sobre Pedro de Navarra: ${ }^{93}$ siguiendo a A. de Yepes, nos recuerda cómo éste «alaba también allí su raro ingenio» para añadir a continuación que:

Se conservan algunos tratados suyos de Filología en lengua española, impresos en Tolosa, en la casa de Colomer. ${ }^{94}$

Evidentemente, se refiere d'Oihénart a los Diálogos de la diferencia del hablar al escrebir, lo que nos sitúa en el centro de lo que vengo adelantando, ya desde la lectura que he realizado de las observaciones primeras de A. de Yepes.

Como se ha elucidado en los últimos años a propósito de una definición precisa de humanismo, la Filología debe ser situada justo en el centro de todo acercamiento que intente ser estricto e integral. Así, F. Rico nos recuerda que «podemos contemplar la historia del humanismo como historia de la alta filología», ${ }^{95}$ y avanzando ya en el humanismo español hacia los hitos que supondrán Nebrija y Salamanca:

la idea de que el fundamento de toda la cultura debe buscarse en las artes del lenguaje, profundamente asimiladas merced a la frecuentación, el comentario y la imitación de los grandes autores de Grecia y Roma; la idea de que la lengua y la literatura clásicas, dechados de claridad y belleza, han de ser la puerta de entrada a cualquier doctrina o quehacer dignos de estima, y que la corrección y la elegancia del estilo, según el buen uso de los viejos maestros de la latinidad, constituyen un requisito ineludible de toda actividad intelectual; la idea de que los studia humanitatis así concebidos, haciendo renacer la Antigüedad, lograrán alumbrar una nueva civilización. ${ }^{96}$

El caso de Pedro de Navarra nos sitúa, sin embargo, en un terreno nuevo que, siguiendo a L. Gil Fernández, podríamos identificar con el del ámbito en

\footnotetext{
${ }^{93}$ A. d'Oihénart, Notitia utriusque Vasconiae tum Ibericae, tum Aquitanicae, qua praeter situm regionis et alia scitu digna, Navarre Regum, Gasconiae Principum, caeterarumque, iniis, insignium vetustae... (1637). Cito por la reprod. facsímil de la 2. ${ }^{a}$ edición de París, 1656, con estudio preliminar de R. Cierbide, y trad. del texto latino, J. Gorosterratzu., Vitoria-Gasteiz, Eusko LegebiltzarraParlamento Vasco, 1992, lib. III, cap. XII.

${ }^{94}$ Ibidem, p. 476.

${ }^{95}$ F. Rico, op. cit., p. 12.

${ }^{96}$ Ibidem, p. 18.
} 
el que se encuentran y se enfrentan el latín y el vernáculo. ${ }^{97}$ Recordemos cómo el discurso ante Pío IV, escrito por Mureto, fue pronunciado en latín, lo que contrasta o se complementa, según se analice, con su alegato previo, realizado en lengua española, circunstancia que generó alabanzas por su gracia y manera en la utilización de esta lengua. D'Oihénart, de hecho, destaca de él precisamente sus tratados «de Filología en lengua española». Con esto la condición de humanista de Pedro de Navarra adquiriría una nueva dimensión. Recordemos que

la lengua latina comenzaba a enfrentarse en toda Europa con las lenguas vulgares, que, en plena madurez, pugnaban por convertirse en instrumentos de cultura, aparte, claro está, de ajustarse mejor a las necesidades actuales de la comunicación. ${ }^{98}$

No obstante, había un hecho claro que hacía posible que Pedro de Navarra pudiera defender sus ideas ante el pontífice en lengua española. No olvidemos «que la lengua española se iba haciendo internacional ("...ya en Italia assí entre damas como entre cavalleros se tiene por gentileza y galanía saber hablar castellano"), pero también era cierto que esto se debía en gran parte a la fuerza de las armas». ${ }^{99}$

En la base de todo esto está la conciencia de ser un pueblo dominante y lo que L. Gil Fernández denomina «el slogan de Nebrija de "la lengua compañera del imperio"» que contribuyeron al desuso del latín como lengua de relación en una monarquía multinacional y plurilingüe. ${ }^{100}$ Además de estas razones políticas, el desuso del latín también contaba entre sus causas con factores que afectaban de lleno a la difusión del conocimiento y de la ciencia. De ello se hace eco un diálogo de la segunda mitad del siglo XVI, conocido como Diálogo de la vida de los pajes de palacio y atribuido a Diego de Hermosilla, en el que, aunque se insiste en la conveniencia de que los caballeros aprendan latín, se añade que:

\footnotetext{
${ }^{97}$ L. Gil Fernández, op. cit., pp. 39-83.

${ }^{98} \mathrm{Ibidem}, \mathrm{p} .59$.

${ }^{99}$ C. Barbolani, «Introducción» a Juan de Valdés, Diálogo de la lengua, Madrid, Cátedra, 1982, pp. 68-69.

${ }^{100}$ L. Gil Fernández, op. cit., p. 60. Vid. E. Asensio, «La lengua compañera del Imperio. Historia de una idea de Nebrija en España y Portugal», Revista de Filología Éspañola, XLIII, 1960, pp. 399-413.
} 
ya no les hace tanta falta como solía, porque casi los mejores libros de philosophía, oratoria y de historias y poesías están traducidos en castellano. ${ }^{101}$

La polémica entre el latín y el vernáculo representaría sólo una primera fase en las cuestiones que atañen a la filología y que Pedro de Navarra abordará en lo sucesivo, ya que en los Diálogos de la diferencia del hablar al escrebir, tal como veremos en un apartado posterior, el autor se inserta en una tradición de tratamientos de la lengua española en los que la preocupación normativa, enfrentada al uso de la misma, va a presidir el estudio y la descripción del idioma, tradición en la que se insertan la Gramática de Nebrija, el Diálogo de la lengua de Juan de Valdés o las ideas gramaticales de Cristóbal de Villalón. ${ }^{102}$

\subsubsection{Fray Jerónimo de San José (1651)}

Como ha escrito S. Montero Díaz, en fray Jerónimo de San José ${ }^{103}$ culmina la ciencia histórica en los tratadistas de preceptiva y metodología del Siglo de Oro. Con él acabaría el período propiamente clásico de los teorizantes de la historia y es descrito como «el heredero de la ya nutrida bibliografía sobre doctrina y metodología de la Historia. Tiene también una rica experiencia de lector: las obras maestras de la historiografía clásica española se han producido ya. Incorpora, pues, las óptimas condiciones para ser el más interesante y sagaz de nuestros metodólogos». ${ }^{104}$

Como culminador de esta tradición, a fray Jerónimo de San José no le era desconocida la labor de los tratadistas españoles, y entre ellos recogerá a Pedro de Navarra:

\footnotetext{
${ }^{101}$ D. de Hermosilla, Diálogo de la vida de los pajes de palacio, ed. D. Mackenzie, Valladolid, Viuda de Montero, 1916, p. 146.

${ }^{102}$ Vid. M. Peñalver Castillo, Estudios de historia de la lingüística española, Almería, Instituto de Estudios Almerienses-Campus Universitario de Almería, 1993, p. 65-94. También C. Codoñer Merino, «Gramáticas y gramáticos», en V. García de la Concha, ed., Literatura en la época del Emperador, pp. 21-36.

${ }^{103}$ Fray J. de San José, Genio de la historia, Zaragoza, Diego Dormer, 1651.

${ }^{104}$ S. Montero Díaz, «Estudio preliminar. La doctrina de la historia en los tratadistas del Siglo de Oro» a Luis Cabrera de Córdoba, De historia para entenderla y escribirla [1611], Madrid, Cosano Imp., 1948, pp. XLIV-XLV. Vid. G. Fontana Elboj, «El Genio de la historia de Fray Jerónimo de San José en el marco de la tratadística histórica del Humanismo», Alazet: Revista de Filología, 14 (2002), pp. 139-156.
} 
Denuestros españoles nohafaltadojamásquien emprendiese de propósito y con erudición este argumento. Entre los cuales escribió doctamente en lengua latina nuestro Juan Costa, catedrático, jurisconsulto y ciudadano de Zaragoza. También en el mismo idioma, el gravísimo y elegantísimo Melchor Cano, en sus Lugares teológicos, con largo discurso de esta materia. Don Pedro de Navarra, obispo de Comenge, en ocho diálogos en lengua española discurre con gravedad y erudición sobre los requisitos de la Historia y del historiador. Últimamente, Luis Cabrera de Córdoba sacó a luz un tratado donde muy de propósito escribe dos difusos libros de Historia, "para entenderla y escribirla». ${ }^{105}$

«Gravedad»y «erudición» son dos nuevos calificativos que vienen a unirse a los que ya he examinado previamente, que completan de hecho lo que avanzaba sobre las cualidades del humanista como intelectual dotado para tratar de las más diversas materias y realizar opciones genéricas acordes con la empresa que acomete, desde una posición en la que la auctoritas que le confiere su formación y estudio en las disciplinas sobre las que versa lo alejan de una escritura superficial o diletante. Al contrario, la introspección necesaria para reflexionar sobre el asunto a tratar va a complementarse con una experiencia práctica en la que no dudará en internarse directamente si atendemos al manuscrito inédito de los Comentarios sobre la figura de Enrique II, donde abandona el diálogo como género en el que habituaba a dar cauce a sus ideas para experimentar con la crónica histórica.

\subsubsection{Nicolás Antonio (1672 / 1696)}

En su Bibliotheca Hispana Nova, ${ }^{106}$ Nicolás Antonio distingue entre dos autores que claramente representan al escritor que ocupa esta revisión. Uno de ellos, con el nombre de «D. PETRUS DE NAVARRA, alias DE LABRIT»:

Joannis Labretii, Navarrae Regis, filius extra legitimas nuptias susceptus, in Hiracensi monasterio Benedictinorum Navarrae regni religiosae vitae olim initiatus sub Veremundi, quo tunc vocabatur, nomine, quod Antonius Yepes chronici Benedictini tomo iv. cent. iv. refert. Convenarum ecclesiae in Vasconia, post Carolum Carrafam, cardinalem sub Paulo IV. patruo ejus, turbarum sibi paulo post fatalium incentorem, creatus

\footnotetext{
${ }^{105}$ Fray J. de San José, op. cit., p. 4.

${ }^{106}$ Finalizada en 1672, la primera edición de la Bibliotheca hispana nova tuvo lugar en Roma en 1696. Cito aquí por la edición de Madrid, Joaquín de Ibarra, 1783 en dos tomos. Manejo para ello la reprod. facsimilar de Madrid, Visor Libros, 1996. Contamos ya con la versión traducida, Biblioteca hispana nueva, o de los escritores españoles que brillaron desde el año MD hasta el de MDCLXXXIV, I-II, Madrid, Fundación Universitaria Española, 1999.
} 
episcopus anno MDLX. Tridentinorum patrum auxit numerum, \& pro Antonio, Navarrae Regem qui se appellabat, apud Pium IV. legationem obivit. Ejus ab ingenio \& doctrina prodiit Hispanae, sibi vernaculae linguae opus dialogorum, quos ita inscriptos vidimus:

Dialogos muy subtiles y notables por el Ilustrisimo y Reverendisimo Señor D. Pedro de Navarra Obispo de Comenge. Caesaraugustae per Joannem Millan 1567. Typis quoque Tolosanis Joannis Colomerii editos Arnaldus Oihenartus refert in Notitia utriusque Vasconiae, ubi de Petro inter Convenarum praesules agit lib. iii. cap. xii. quemadmodum \& Sanmarthani fratres agunt in Gallia Christiana \& Convenarum Episcopis. Tribus quidem partibus opus totum constat: Prima pars continet quinque dialogos, De qual debe ser el Coronista del Principe, ad Philippum II. Austriacum; in quibus appellat se a consiliis Regis Christianissimi. Secunda pars quatuor dialogos De la Diferencia de la vida rustica a la noble, ad marchionem Mondexarensem, senatus Castellae praesidem. Tertia xxxi. dialogos, De la Preparacion de la muerte, ad Franciscum de Eraso, primum a secretis Regiis, cui ob communem amicitiam \& patriam hanc illi partem se dedicare ait. In primo istorum dialogorum, quibus de chronographi agit munere, Basilius quidam dialogistam induxit, quem scripsisse vitas Caroli Imperatoris \& Pauli III. Papae annotatum legitur. ${ }^{107}$

Y el otro, que corresponde a la cita precedente, «PETRUS NAVARRO»:

nobis alia ignotus, scripsisse dicitur: Dialogum de Discrimine legendi ac scribendi. Tolosae editum a Jacobo Colmerio. Italicum quoque Petro Navarro alterum opus tribuitur ita inscriptum, dialogisticum \& ipsum: Dell' Eternita dell' Anima. ${ }^{108}$

Esta confusión de Nicolás Antonio originó una serie de errores posteriores entre los que necesariamente debieron recurrir al primer atisbo de lo que podría considerarse una historiografía literaria, en la que se aunaban el afán nacionalista y el quehacer erudito de una época en la que, según A. Rallo Gruss, «el filólogo tiende a transformarse en erudito anticuario o arqueólogo, y el gramático procura la sistematización útil de la lengua». ${ }^{109}$

\footnotetext{
${ }^{107}$ A. Nicolás Antonio, op. cit., pp. 220-221

${ }^{108}$ Ibidem, p. 221.

109 A. Rallo Gruss, La prosa didáctica en el siglo XVII, Madrid, Taurus, 1988, p. 21. Como señala la autora, la Bibliotheca hispana nova hacía «salir a la crítica literaria del mero comentario personal al de la investigación histórica rigurosa». Para los antecedentes, vid. R. Ricard, «De la critique humaniste
} 
Entre las consecuencias erróneas más frecuentes encontraremos la que lleva a algunos historiodores y filólogos a pensar que el bibliófilo español ignoraba la existencia de los Diálogos de la diferencia del hablar al escrebir y de los Diálogos de la eternidad del ánima. Ni G. Ticknor ${ }^{110}$ ni el Conde de la Viñaza ${ }^{111}$ advirtieron este error de Nicolás Antonio, y que un mismo autor estaba desdoblado en dos entradas, error no irreparable, e imperdonable para los receptores de la obra de Nicolás Antonio, ya que ambas entradas figuran en un orden consecutivo en la misma página. De ahí que tanto Ticknor como el conde de la Viñaza realicen conjeturas sobre la razón por la que el bibliófilo del XVII no se ocupó de los Diálogos de la diferencia del hablar al escrebir.

La única razón de la que podría valerme para aventurar una explicación plausible de esta confusión no deja de ser más que hipotética, pero puede tener visos de realidad. Está claro que Nicolás Antonio no llegó a manejar las ediciones de los diálogos que se imprimieron en Toulouse en casa de Jacobo Colomerio. Ni las series individuales de los Diálogos de la diferencia del hablar al escrebir ni las de los Diálogos de la eternidad del ánima, ni tampoco las tres series agrupadas bajo el título de Diálogos de varios asumtos. Las dos primeras, al no incluirse entre los Diálogos muy subtiles y notables que se reeditaron posteriormente en Zaragoza,

\footnotetext{
à la critique des "Lumières". Esquisse d'une évolution», en A. Redondo, ed., op. cit., pp. 349-370; y L. Terracini, «Crítica literaria. ¿Historia literaria?», en V. García de la Concha, ed., Literatura en la época del Emperador, pp. 37-52, y recientemente, las páginas más esclarecedoras sobre la evolución de la historiografía literaria española, siguiendo un proceso de deconstrucción de todos los elementos que la han ido lastrando hasta conducirla aun estado de postración y anquilosamiento, debidas a J. Lara Garrido, «Historia y concepto (sentido y pertinencia del marbete Siglo de Oro)», Del Siglo de Oro (métodos y relecciones), Madrid, Universidad Europea / CEEs Ediciones, 1997, págs. 23-56, que deben completarse con su introducción a E. Orozco Díaz, La literatura en Andalucía (De Nebrija a Ganivet), edición, introducción y anotaciones de J. Lara Garrido, Málaga, Universidad de Málaga, 2007. La introducción, que lleva por título «Sobre la "Historia de la literatura en Andalucía». Materiales y reflexiones», pp. 11-52, discurre por unos derroteros mucho más amplios que los que ese título lleva a suponer, pues su análisis de los intersticios de la crisis de la historia literaria tradicional (o nacional), su examen de las limitaciones originarias de la literatura nacional como objeto de conocimiento, del carácter retardatario de la perspectiva regional, con una serie de anotaciones a partir de la recepción de la obra bibliográfica de Nicolás Antonio, que culmina en la propuesta de un encuadre y razones que posibiliten una práctica historiográfica renovadora, se convierten en inexcusable punto de partida para los caminos de la filogía española.

${ }^{110}$ G. Ticknor, History of Spanish Literature, I-III, Londres, Murray, 1849. Cito por la trad. castellana con adiciones y notas críticas de Pascual de Gayangos y Enrique de Vedia, Madrid, La Publicidad, 1851-1856 en 4 tomos, en su reedición de Buenos Aires, 1948. La referencia a Pedro de Navarra en el tomo II, pp. 80-81.

${ }^{111}$ Conde de la Viñaza, op. cit., año 1590, pp. 455-457, cols. 906-910.
} 
sólo fueron conocidas por Nicolás Antonio posiblemente de oídas y con datos bastante confusos. Esto nos hace pensar, dado lo escueto y superficial del espacio que dedica a los Diálogos de la diferencia del hablar al escrebir y a los Diálogos de la eternidad del ánima, incluyendo el hecho de que no cite en ninguno de los dos casos sus títulos adecuadamente, que estos dos diálogos sólo llegaron a su conocimiento a través de referencias indirectas. Es difícil que hubiera tenido un contacto visual directo con estas obras, dado que en todas las portadas siempre se especifica que Pedro de Navarra es bien el autor bien el que dicta, y se declara su cargo eclesiástico, obispo noveno de Comenge.

El hecho de que cite el título de los Diálogos de la diferencia del hablar al escrebir en latín (Dialogum de Discrimine legendi ac scribendi) y el de los Diálogos de la eternidad del ánima en italiano (Dell' Eternita dell' Anima) podría dar paso a una serie de conjeturas en las que no voy a profundizar aquí, pero que indudablemente deben ser tenidas en cuenta para investigaciones bibliográficas futuras. De esas referencias se deduce la posible existencia de un original o un manuscrito en latín de los primeros diálogos o, incluso, la posible existencia de una edición italiana a nombre de un «Petrus Navarro» al que Nicolás Antonio afirma desconocer. Retomando la línea que vengo trazando sobre los elementos, iterativos y conceptualmente arquetípicos y vacíos del contenido original, que irían conformando la imagen de un modelo que responde al nombre de Pedro de Navarra, tan confuso y mediatizado por el olvido ya a finales del XVII como para dar lugar a que ese modelo se escinda en dos autores distintos, las fuentes que maneja Nicolás Antonio vuelven a ser fundamentalmente A. de Yepes y A. d'Oihénart. Del primero se toman los datos sobre su origen y su profesión como monje, de nombre Veremundo, en el monasterio benedictino de Irache. Del segundo, su nombramiento como obispo de Cominges tras la muerte de Carlos Carafa, su asistencia a Trento y su labor cerca de los reyes navarros. La nota que nos interesa aquí es:

Ejus ab ingenio \& doctrina prodiit Hispanae, sibi vernaculae linguae opus dialogorum, quos ita inscriptos vidimus. ${ }^{112}$

Esto no deja de prestarse a una confusión inevitable, ya que para el «Petrus De NAvARrA, alias Labrit», autor de los diágos publicados en Zaragoza, dado que se documenta en A. d'Ohiénart, y precisamente en la

\footnotetext{
${ }^{112}$ A. Nicolás Antonio, op. cit., p. 220.
} 
obra que hemos revisado en un apartado anterior, donde se afirmaba que «se conservan algunos tratados suyos de Filología en lengua española, impresos en Tolosa, en la casa de Colomer», cabría pensar en una lectura errónea o en un manejo de la fuente no de primera mano, ya que el dato proporcionado por d'Ohiénart, por su especial relevancia, difícilmente debió pasársele por alto al quehacer erudito de Nicolás Antonio, y dar como resultado la referencia genérica a la escritura de diálogos en lengua española.

Tres son los aspectos, dejando de lado este punto, que destacan en esta observación. Por una parte, la ya lexicalizada referencia al «ingenio» del autor, de la que ya se han desprendido las valencias de "peregrino» $\mathrm{y}$ «raro» para dar paso a algo que en sí es novedoso. Ya no se trata sólo de su habilidad retórica, por denominarla así, sino también de la enjundia de su «doctrina»,la formulación de una preceptiva que debe entenderse como propósito de educación y formación moral del lector: en efecto, los diálogos que Nicolás Antonio menciona a continuación se centran en asuntos que conciernen a tres situaciones prácticas, tres momentos posibles en la experiencia del hombre, sobre los que el autor elabora una formulación doctrinal a fin de que pueda demostrarse su validez práctica. Se trata de abordar cómo debe ser el cronista del príncipe, es decir, si debe atenerse a su ética como historiador o subordinarse a los intereses de los mandatarios; de las virtudes que esgrime un rústico en tanto que hombre natural frente a los artificios y la doblez del noble; o de la preparación de la muerte como consejos que se van engarzando y que van dirigidos a una figura pública del momento, el secretario Francisco de Eraso, con todos los consecuentes éticos y religiosos que de ello se desprende.

Estamos ya deslizándonos, dentro de la amplitud del término humanista al que he recurrido desde el inicio de esta revisión, desde lo estrictamente filológico, es decir, el dominio en las disciplinas de gramática, retórica, poesía, historia y filosofía moral, hacia un humanismo aplicado que desea una transformación y que desea formar al que atiende a una doctrina por vía de la oratoria o de la escritura. Como ha apuntado F. Rico, los

mayores humanistas de la edad anterior habían sido filólogos de primera fila, curtidos especialistas en cuanto tuviera que ver con la Antigüedad, pero a la vez, partiendo del clasicismo, habían interrumpido en otros campos, de la filosofía a la política, de la geografía a la religión, con el designio de transformarlos profunda y aun sustancialmente. ${ }^{113}$

${ }^{113}$ F. Rico, op. cit., p. 75. 
Se nos recuerda que la auténtica eruditio, tal como proclamaba Leonardo Bruni, unía las palabras y las cosas: «litterarum peritiam cum rerum scientiam coniungit». ${ }^{114}$ Talcomoexponíamosanteriormente, «elsabereranecesariamente activo, impregnaba la vida privada y repercutía en la pública. En parte, la actitud obedecía al ideal retórico que configuraba al humanismo desde los mismos fundamentos, porque la eloquentia de los retóricos es en primer lugar arte de persuasión, manera de diálogo y presencia en la polis». ${ }^{115}$

$\mathrm{Y}$ en este punto es justamente donde se insertan los «vernaculae linguae opus dialogorum» a los que se refiere Nicolás Antonio, ya que el cauce expresivo que escoge Pedro de Navarra es precisamente el diálogo, un género que, como nos recuerda A. Prieto, es una forma de expresión que provenía libre de la Antigüedad «sin ningún precepto realmente válido para su orden o estructura y que el Renacimiento podía recoger en su ausencia de ataduras escolásticas». ${ }^{116} \mathrm{El}$ autor nos recuerda que el diálogo posee una relativa herencia del poema didáctico:

como el sistema literario que mediante la aplicación a lo verosímil tendía a persuadir, al discere, y que era también un aprender para el propio autor o consolatio. ${ }^{117}$

En esta forma y retrayéndonos al término «doctrina» que emplea Nicolás Antonio, enlazamos con el hecho de que los diálogos, como afirma A. Rallo,

cumplen con una intención didáctica o divulgativa, correspondiendo al método humanista de formar al hombre, no sólo en el plano intelectual sino también moral. ${ }^{118}$

${ }^{114}$ De studiis et litteris, apud F. Rico, op. cit., p. 75.

${ }^{115}$ F. Rico, op. cit., p. 75.

${ }^{116}$ A. Prieto, La prosa española del siglo XVI, I, Madrid, Cátedra, 1986, p. 101.

117 Ibidem.

${ }^{118}$ A. Rallo Gruss, La Escritura Dialéctica, p. 45. 